Article

\title{
Temperature Disturbance Management in a Heat Exchanger Network for Maximum Energy Recovery Considering Economic Analysis
}

\author{
Ainur Munirah Hafizan ${ }^{1}$, Jiří Jaromír Klemeš ${ }^{2, *}$, Sharifah Rafidah Wan Alwi ${ }^{1}$, \\ Zainuddin Abdul Manan ${ }^{1}$ and Mohd Kamaruddin Abd Hamid ${ }^{1}$
}

1 Process Systems Engineering Centre (PROSPECT), Research Institute for Sustainable Environment (RISE), School of Chemical and Energy Engineering, Universiti Teknologi Malaysia (UTM), 81310 Johor Bahru, Johor, Malaysia; ainurhafizan@yahoo.com (A.M.H.); syarifah@utm.my (S.R.W.A.); dr.zain@utm.my (Z.A.M.); kamaruddinhamid@utm.my (M.K.A.H.)

2 Sustainable Process Integration Laboratory - SPIL, NETME Centre, Faculty of Mechanical Engineering, Brno University of Technology - VUT BRNO, Technická 2896/2, 61669 Brno, Czech Republic

* Correspondence: klemes@fme.vutbr.cz; Tel.: +420-541-144-985

Received: 31 December 2018; Accepted: 11 February 2019; Published: 13 February 2019

check for updates

\begin{abstract}
The design of heat exchanger networks (HEN) in the process industry has largely focused on minimisation of operating and capital costs using techniques such as pinch analysis or mathematical modelling. Aspects of operability and flexibility, including issues of disturbances affecting downstream processes during the operation of highly integrated HEN, still need development. This work presents a methodology to manage temperature disturbances in a HEN design to achieve maximum heat recovery, considering the impact of supply temperature fluctuations on utility consumption, heat exchanger sizing, bypass placement and economic performance. Key observations have been made and new heuristics are proposed to guide heat exchanger sizing to consider disturbances and bypass placement for cases above and below the HEN pinch point. Application of the methodology on two case studies shows that the impact of supply temperature fluctuations on downstream heat exchangers can be reduced through instant propagation of the disturbances to heaters or coolers. Where possible, the disturbances have been capitalised upon for additional heat recovery using the pinch analysis plus-minus principle as a guide. Results of the case study show that the HEN with maximum HE area yields economic savings of up to $15 \%$ per year relative to the HEN with a nominal HE area.
\end{abstract}

Keywords: pinch analysis; heat exchanger network (HEN) design; plus-minus principle; supply temperature; disturbances; maximum energy recovery; bypass; economic evaluation

\section{Introduction}

Heat integration has been a well-established energy saving technique for the chemical process industry since the global energy crisis in the 1970s [1]. There has also been extensive development of pinch analysis methodologies for industrial heat exchanger network (HEN) design focusing on minimisation of operating and capital costs [2]. The developed methodologies typically assume that process parameters such as supply/target temperatures and stream flowrates are fixed [3]. In practice, these process parameters may fluctuate due to plant start-ups/shut-downs, changes in feed or product demand as well as quality, changes in environmental conditions and other operational disturbances. The impact of these parameter changes influences energy related-decision making as a step for efficient energy management in the industry $[4,5]$. The extent to which a HEN is able to cope with disturbances is 
known as flexibility [3]. Previous works have included flexibility, safety, controllability and operability in the pre-design stage.

Marselle et al. [6] pioneered the study of operability considerations for HENs. They proposed a manual combination of several resilient designs with maximum energy efficiency under different worst-case scenarios. Hafizan et al. [7] proposed the controllability of HEN under uncertainty by having a large heat exchanger area. This method is able to recover maximum heat with minimum utility. The paper was also partly presented at the 13th SDEWES conference and proceedings. Linnhoff and Kotjabasakis [8] introduced the concept of downstream paths to identify disturbance propagation paths through HEN. Supply temperature and feed flowrate disturbances occurring at the feed stream of heat exchangers can affect the target temperatures of processes located downstream of the heat exchanger path. HEN modification, therefore, may need to be performed to reject the process disturbances.

Escobar et al. [9] introduced a computational framework for the synthesis of controllable and flexible HENs over a specified range of inlet temperatures and flow rate variations using a decentralised control system. This framework comprised two stages-the HEN design and the operability analysis and adjustment of control variables during operation in the presence of uncertain parameters. Hafizan et al. [10] developed a pinch analysis-based methodology, which considered both safety and operability aspects in HEN synthesis. The concept of downstream paths suggested by Linnhoff and Kotjabasakis [8] was used for the assessment of flexibility and structural controllability. Čuček and Kravanja [11] proposed a novel three-step methodology for HEN retrofit with fixed and flexible designs for large-scale total sites (TS). This method modified the HEN by forming profitable heat exchanger matches with improved utility consumption as well as by proposing intermediate utility production.

Most recent works have developed a multi-period formulation for the synthesis of flexible HENs. Isafiade and Short [12] proposed a three-step approach for improving the degree of flexibility of a multi-period HEN with unequal periods. However, this method is unable to cater for all the possible uncertainties of process parameters. Miranda et al. [13] recently proposed three sequential steps represented by linear programming (LP), multi-linear programming (MILP) and non-linear programming (NLP) for the synthesis of multi-period HEN. The same heat transfer can be operated under different operating conditions in the multi-period [13]. Kang and Liu [14] developed a three-step method for designing a flexible multi-period HEN when the disturbances of operating parameters occurred in sub-periods. The flexibility of nominal multi-period HEN is first determined and analysed prior to identifying the bottlenecks. As a next step, the design of flexible multi-period HEN is finalised by solving the sub-period debottlenecking model.

Several authors have considered the operability issues at the early stages of the process design. The need for this s widely accepted and has motivated the integration of process design and control (IPDC). Narraway and Perkins [15] and Walsh and Perkins [16] were the among the earliest to take into account the general mathematical programming techniques for the simultaneous design and control problem using dynamic process models. Recently, Abu Bakar et al. [17] introduced a new model-based IPDC of HEN which is decomposed into four hierarchical sequential stages. The proposed methodology recommends a solution that satisfies the design, control and economic criteria.

The optimal HEN with unclassified hot/cold process streams was discussed in the work of Kong et al. [18], Quirante et al. [19] and Onishi et al. [20]. All these works depend on the process operating conditions to finalise the classification of process streams. Kong et al. [18] presented mixed-integer nonlinear programming (MINLP) for the heat integration model which accounts for unclassified process streams and variable stream temperatures and flowrates. Quirante et al. [19] later extended the disjunctive model of the pinch location method proposed by Quirante et al. [21] and work by Kong et al. [18] for the simultaneous process optimisation and heat integration. This work is also extended for the isothermal process streams, multiple utilities and area estimation of HEN. The area estimation is done based on the vertical heat transfer between the hot and cold balanced composite curves. Onishi et al. [20] proposed an optimisation model to enhance the work and HENs energy efficiency and cost-effective synthesis considering the unclassified process streams. It combined 
the methods of mathematical programming and pinch location while adjusting the pressure and temperature of unclassified streams.

State-of-the-art studies on HEN flexibility, show that there are a few key limitations associated with the existing methods. In these previous works, the optimal design of HEN synthesis operated under uncertain operating parameters were considered with an appropriate strategy for control and operation. The control variables were assumed to be adjusted during the operation to improve the flexibility of HEN. However, several possible HEN configurations were needed for each of the scenarios in order to increase the flexibility and some exchanger area adjustment was required during the operation. Besides that, heuristics to guide heat exchanger sizing and bypass placement, and which can be applied in all cases have not been introduced. The understanding of how the temperature fluctuation in HEN affects the amount of heat recovery is still not clearly understood.

This work presents a methodology to manage temperature disturbances in HEN design for maximum heat recovery. The impact of the supply temperature fluctuations on utility consumption, heat exchanger sizing and bypass placement are studied to ensure the target temperatures of affected streams are achieved. At the same time, reducing the impact of the fluctuation on downstream heat exchangers and the immediately propagation of the disturbances to heaters or coolers is desired. Where possible, taking advantage of the disturbances for additional heat recovery is also desirable. The plus-minus principle for process changes are used and new heuristics are introduced to guide heat exchanger sizing and bypass placement. Linnhoff and Vredeveld [22] have introduced the plus-minus principle for visualising the impact of process modifications on the minimum utility target using the composite curves (CC). Chew et al. [23] applied the plus-minus principle for process modification aimed at maximising energy savings for total site heat integration (TSHI). This methodology enabled designers to identify the potential process changes to maximise energy recovery and reduce utility consumption. Song et al. [24] further implemented the plus-minus principle for inter-plant heat integration (IPHI) for case studies involving threshold problems. The proposed methodology provides a simple technique of rapidly assessing the effect of supply temperature $\left(T_{S}\right)$ fluctuations in heat recovery and utility reduction without the need for detailed process simulation.

\section{Methodology}

This section describes the methodology that was developed to manage supply temperature disturbances through modification of a conventional heat exchange network. By planning the right size for the heat exchangers, and by utilising the bypass streams, a HEN can be designed with the flexibility to cope with supply temperature disturbances. An illustrative case study of a HEN experiencing supply temperature disturbances on each process stream is used to demonstrate the applicability of the methodology. For the case study, disturbances are assumed to occur at all supply temperatures $\left(\mathrm{T}_{\mathrm{SH} 1}, \mathrm{~T}_{\mathrm{SH} 2}, \mathrm{~T}_{\mathrm{SH} 3}, \mathrm{~T}_{\mathrm{SC} 1}, \mathrm{~T}_{\mathrm{SC} 2}\right.$ and $\left.\mathrm{T}_{\mathrm{SC} 3}\right)$ with a deviation of $\pm 5^{\circ} \mathrm{C}$. The manipulated variables for process control include heat exchangers, bypasses and utility flowrates of coolers and heaters. The controlled variables are all the target temperatures $\left(\mathrm{T}_{\mathrm{tH} 1}, \mathrm{~T}_{\mathrm{tH} 2}, \mathrm{~T}_{\mathrm{tH} 3}, \mathrm{~T}_{\mathrm{tC} 1}, \mathrm{~T}_{\mathrm{tC2}}\right.$ and $\left.\mathrm{T}_{\mathrm{tC} 3}\right)$.

\subsection{Step 1: Stream Data Extraction with Disturbances}

Table 1 shows the stream data which are used to illustrate the effect of disturbances on maximum energy recovery HEN. There are three hot streams (H1, H2 and H3) and three cold streams (C1, C2 and C3) involved in the process. The required data for the pinch study includes the supply temperature, $\mathrm{T}_{\mathrm{s}}$; target temperature, $\mathrm{T}_{\mathrm{t}}$; heat capacity flowrate, $\mathrm{FC}_{\mathrm{p}}$; enthalpy, $\Delta \mathrm{H}$ and the supply temperature fluctuation temperature range. The minimum temperature difference, $\Delta \mathrm{T}_{\min }$ is set as $10^{\circ} \mathrm{C}$. 
Table 1. Stream data for nominal operation.

\begin{tabular}{ccccc}
\hline Stream & $\begin{array}{c}\text { Supply Temperature, } \\
\mathbf{T}_{\mathbf{s}}\left({ }^{\circ} \mathbf{C}\right)\end{array}$ & $\begin{array}{c}\text { Target Temperature, } \\
\mathbf{T}_{\mathbf{t}}\left({ }^{\circ} \mathbf{C}\right)\end{array}$ & $\begin{array}{c}\text { Heat Capacity Flowrate, } \\
\mathbf{F C}_{\mathbf{P}}\left(\mathbf{M W} /{ }^{\circ} \mathbf{C}\right)\end{array}$ & $\begin{array}{c}\text { Enthalpy, } \\
\boldsymbol{\Delta} \mathbf{H}(\mathbf{M W})\end{array}$ \\
\hline Hot 1 (H1) & $310 \pm 5$ & 270 & 3 & -120 \\
Hot 2 (H2) & $235 \pm 5$ & 120 & 4 & -460 \\
Hot 3 (H3) & $270 \pm 5$ & 60 & 5 & -1050 \\
Cold 1 (C1) & $40 \pm 5$ & 220 & 3 & 540 \\
Cold 2 (C2) & $90 \pm 5$ & 290 & 5 & 1000 \\
Cold 3 (C3) & $240 \pm 5$ & 300 & 7 & 420 \\
\hline
\end{tabular}

\subsection{Step 2: Perform Maximum Energy Recovery Targeting for the Nominal Case}

The maximum energy recovery (MER) targets are determined for the nominal case (without disturbances) by using pinch analysis targeting methods such as the problem table algorithm or composite curves by Linnhoff and Flower [25] or streams temperature vs enthalpy plot (STEP) by Wan Alwi and Manan [26]. The targeted minimum hot utility requirement $\mathrm{Q}_{\mathrm{Hmin}}$ is $450 \mathrm{MW}$ and the minimum cold utility requirement $\mathrm{Q}_{\mathrm{Cmin}}$ is $180 \mathrm{MW}$. The hot pinch temperature, $\mathrm{T}_{\text {Pinch, hot }}$ is at $250^{\circ} \mathrm{C}$ and the cold pinch temperature, $\mathrm{T}_{\text {Pinch, cold }}$ is at $240{ }^{\circ} \mathrm{C}$. Figure 1 shows the composite curves of the nominal case.

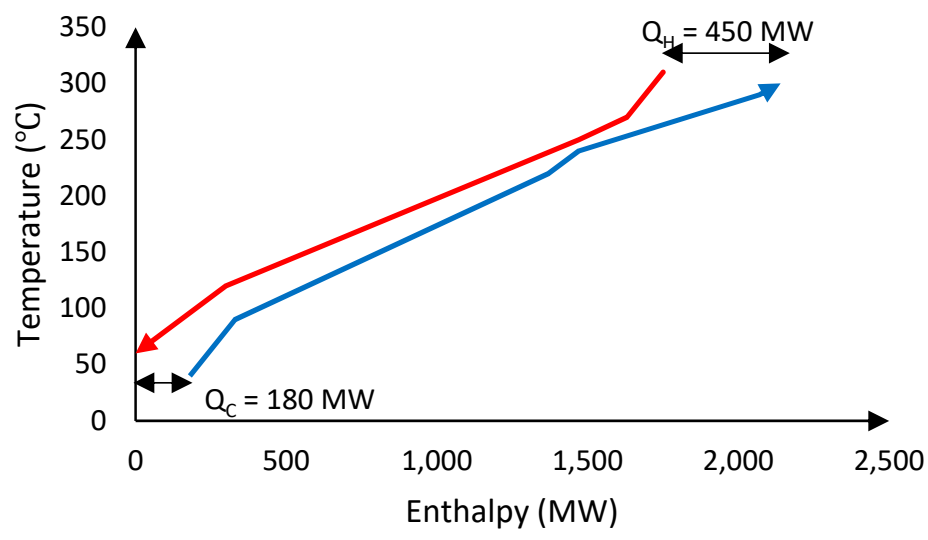

Figure 1. Composite curves for the nominal case.

\subsection{Step 3: Construct the Grid Diagram (GD)}

The nominal maximum energy recovery (MER) network is designed using the pinch design method by Linnhoff and Flower [25] and drawn on the grid diagram (GD) shown in Figure 2. Based on the feasibility criteria proposed by Linnhoff and Hindmarsh [27], streams matching above the pinch have to meet the criterion of $\mathrm{CP}_{\mathrm{COLD}} \geq \mathrm{CP}_{\mathrm{HOT}}$ and streams matching below the pinch have to meet the criterion of $\mathrm{CP}_{\mathrm{HOT}} \geq \mathrm{CP}_{\mathrm{COLD}}$, at the pinch location. Equations (1) and (2) are used to determine the enthalpy balances for hot and cold streams.

$$
\begin{gathered}
\mathrm{Q}_{\mathrm{HE}, \text { hot }}=\mathrm{FC} \mathrm{p}_{\text {hot }} \cdot\left(\mathrm{T}_{\text {hot,in }}-\mathrm{T}_{\text {hot,out }}\right) \\
\mathrm{Q}_{\mathrm{HE}, \text { cold }}=\mathrm{FC} \mathrm{p}_{\text {cold }} \cdot\left(\mathrm{T}_{\text {cold,in }}-\mathrm{T}_{\text {cold,out }}\right)
\end{gathered}
$$




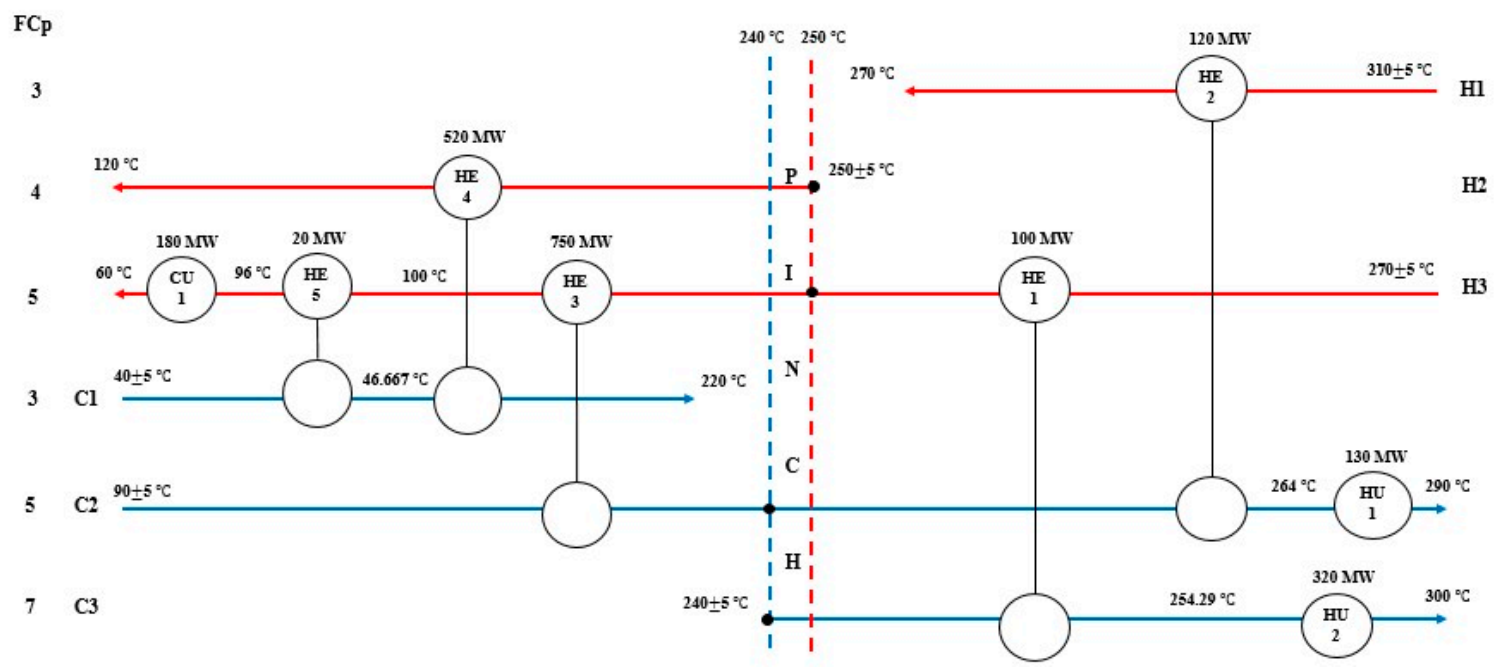

Figure 2. Maximum energy recovery (MER) heat exchanger network (HEN) design for the nominal case.

\subsection{Step 4: Manage Fluctuating Ts (Ts Disturbances) in HEN to Achieve MER}

The steps to manage fluctuating $T_{S}$ in HEN to achieve $T_{t}$ and MER can be defined in three stages. The first stage describes the effect of increasing or decreasing $T_{S}$ on the hot and cold streams energy requirement. The second stage provides the fundamental theory of the plus-minus principle. The final stage explains the effect of $T_{S}$ fluctuation on utilities based on the plus-minus principle. Heuristics are proposed for each disturbance scenario that necessitates bypass placement and valve opening, as well as the correct heat exchanger sizing to maximise utility savings.

\subsubsection{Effect of Increasing or Decreasing $\mathrm{T}_{\mathrm{S}}$ on Hot and Cold Streams}

Figure 3 shows the effect of increasing or decreasing $T_{S}$ for a hot stream. The target temperature, $T_{t}$ is assumed to be maintained. An example of this situation is a fluctuating reactor exit temperature. Before the stream enters the next unit operation, the $T_{t}$ should be maintained at the setpoint value. From Figure 3, it can be seen that increasing $T_{S}$ for hot stream results in an increase in enthalpy, $\Delta H$, while decreasing $T_{S}$ results in a decrease in $\Delta \mathrm{H}$.

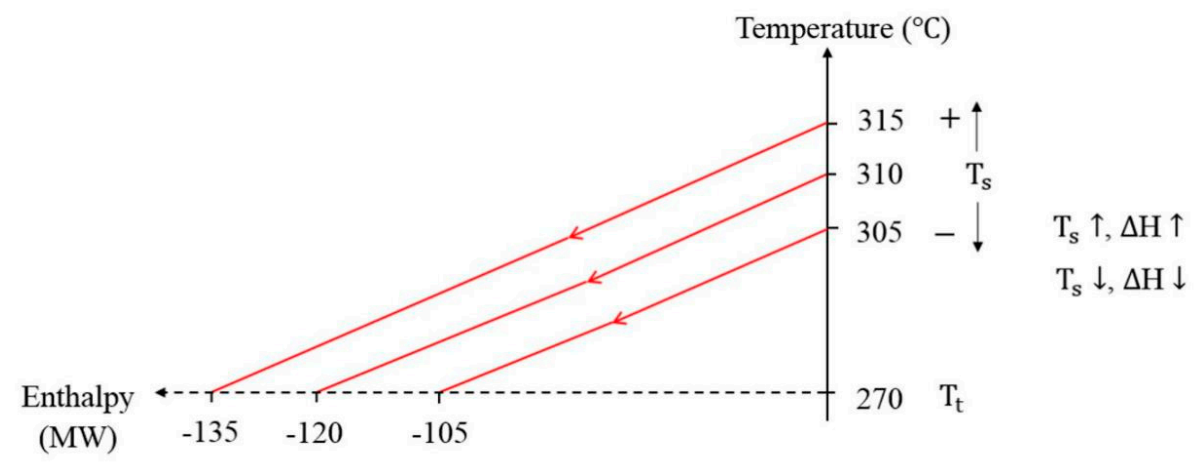

Figure 3. Effect of increasing or decreasing supply temperature $\left(\mathrm{T}_{\mathrm{S}}\right)$ on a hot stream.

On the other hand, Figure 4 shows the effect of increasing or decreasing $T_{S}$ on a cold stream. From the figure, it can be seen that an increase in $T_{S}$ results in an increase in $\Delta \mathrm{H}$ while a decrease in $T_{S}$ results in a decrease in $\Delta \mathrm{H}$. The target temperature, $\mathrm{T}_{\mathrm{t}}$ is also assumed to be maintained. An example of this situation is a feed stream coming from a storage tank experiencing temperature fluctuations due to changes in ambient conditions as a result of weather changes in a four-season country. 


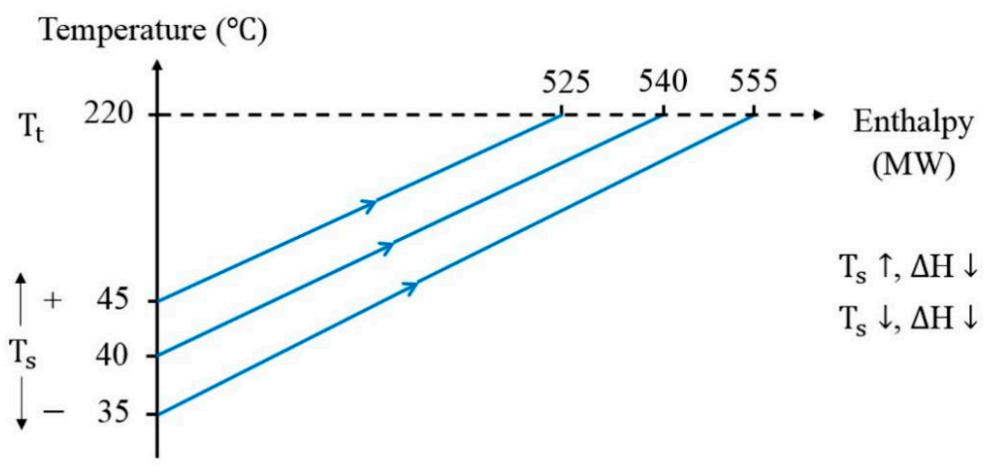

Figure 4. Effect of increasing or decreasing $\mathrm{T}_{\mathrm{S}}$ on a cold stream.

\subsubsection{The Plus-Minus Principle Concept}

Figure 5 shows the effect of plus-minus principle on composite curves (CC), as explained by Linnhoff and Vredeveld [22]. Above the pinch, increasing the enthalpy of a hot stream and decreasing the enthalpy of a cold stream decreases the minimum hot utility target, $\mathrm{Q}_{\mathrm{H} \text {,min }}$. Doing the reverse above the pinch increases $\mathrm{Q}_{\mathrm{H} \text {,min }}$. Below the pinch, increasing the enthalpy of a cold stream and decreasing the enthalpy of a hot stream decreases the minimum cold utility target, $\mathrm{Q}_{\mathrm{C}, \mathrm{min}}$. Doing the reverse below the pinch increases $Q_{C, \text { min }}$.

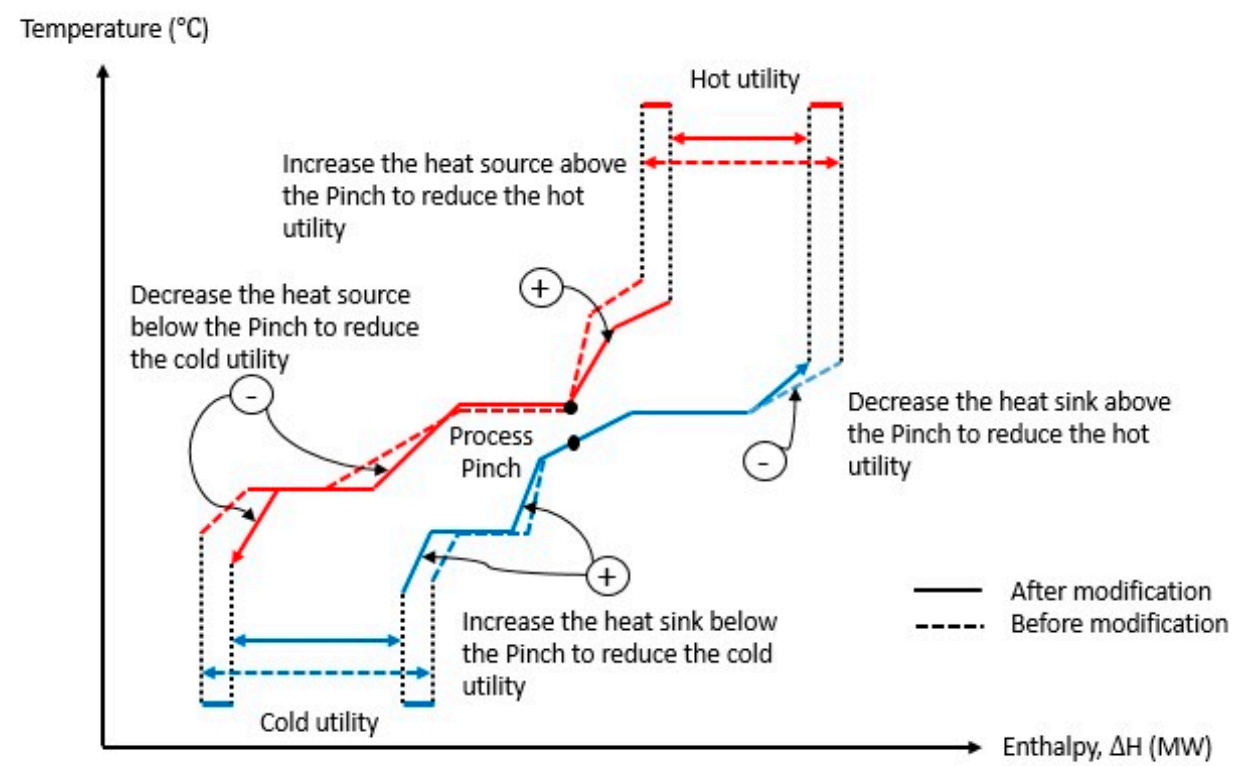

Figure 5. The plus-minus principle (amended from [22]).

\subsubsection{Control Mechanism Decision by Using the Plus-Minus Principle}

The plus-minus principle can be used to describe the effect of disturbances on HEN operation, and how HEN can be controlled. As shown in Step 4(i), the increase or decrease in supply temperature, $T_{S}$ of the hot or cold stream results in an increase in either $Q_{H}$ or $Q_{C}$; or a decrease in $Q_{H}$ or $Q_{C}$. For effective control of $\mathrm{T}_{\mathrm{t}}$, utility units such as heaters and coolers have been widely used in process plants. Utility heaters/coolers are typically placed after a series of heat exchangers to supplement stream heating or cooling. A bypass, on the other hand, functions as a mechanism for controlling process stream parameters including for disturbance rejection.

A bypass placed on the hot stream side can be described using Equation (3) while a bypass placed on the cold stream side can be described using Equation (4) [28]. $\mathrm{T}_{\mathrm{t}}^{\mathrm{h}}$ represents the target temperature of the heat exchanger at hot the stream side, $\mathrm{T}_{\mathrm{t}}^{\mathrm{c}}$ represents the target temperature of the heat exchanger at a cold stream side; $\mathrm{T}_{\mathrm{o}}^{\mathrm{h}}$ represents the outlet temperature of the heat exchanger at hot stream side, $\mathrm{T}_{\mathrm{o}}^{\mathrm{c}}$ 
represents the outlet temperature of the heat exchanger at a cold stream side; $\mathrm{T}_{\mathrm{s}}^{\mathrm{h}}$ represents the supply temperature of the heat exchanger at hot stream side, $\mathrm{T}_{\mathrm{S}}^{\mathrm{c}}$ represents the supply temperature of heat exchanger at a cold stream side; $\mathrm{u}^{\mathrm{b}}$ represents the bypass fraction; $\mathrm{u}^{\mathrm{h}}$ represents the stream fraction at hot stream side, $\mathrm{u}^{\mathrm{c}}$ represents the stream fraction at cold stream side. Application of Equations (1) and (2) is explained next, in the context of heuristics development.

$$
\begin{gathered}
\mathrm{T}_{\mathrm{t}}^{\mathrm{h}}=\left(1-\mathrm{u}^{\mathrm{h}}\right) \mathrm{T}_{\mathrm{o}}^{\mathrm{h}}+\mathrm{u}^{\mathrm{b}} \mathrm{T}_{\mathrm{s}}^{\mathrm{h}} \\
\mathrm{T}_{\mathrm{t}}^{\mathrm{c}}=\left(1-\mathrm{u}^{\mathrm{c}}\right) \mathrm{T}_{\mathrm{o}}^{\mathrm{c}}+\mathrm{u}^{\mathrm{b}} \mathrm{T}_{\mathrm{s}}^{\mathrm{c}}
\end{gathered}
$$

New heuristics have been introduced in this work as guides for the appropriate placement of a bypass and sizing of the heat exchanger that can reduce hot and cold utilities in cases with recurring Ts disturbances. Each proposed heuristic shall refer to the plus-minus principle of process changes. Applicability of the heuristics is explained using a case study.

Below the pinch:

Observation 1. Decreasing $T_{S}$ for a hot or cold stream below the pinch results in decreasing $Q_{C}$.

The first observation states that decreasing $\mathrm{Ts}$ for a hot or cold stream located below the pinch results in $\mathrm{Q}_{\mathrm{C}}$ decreasing. For example, the $\mathrm{T}_{\mathrm{S}}$ of cold stream $\mathrm{C} 1$ decreases from $40^{\circ} \mathrm{C}$ to $35^{\circ} \mathrm{C}$. As shown in Figure 4, decreasing $\mathrm{T}_{\mathrm{S}}$ on cold stream $\mathrm{C} 1$ increases $\mathrm{C} 1$ enthalpy by $15 \mathrm{MW}$. Based on the plus-minus principle, since stream $\mathrm{C} 1$ is located below the pinch, it can be used to recover more energy. This results in a reduction of CU2 cold utility from $180 \mathrm{MW}$ to $165 \mathrm{MW}$, which is desirable. In order to control the target temperature of stream $\mathrm{C} 1$ at $220^{\circ} \mathrm{C}$, the $\mathrm{C} 1$ flowrate entering $\mathrm{HE} 5$ is selected as a manipulated variable. The duty of HE5 is increased from $20 \mathrm{MW}$ to $35 \mathrm{MW}$ to allow more heat to be exchanged. To be able to do this, HE5 should be designed with a bigger area to accommodate up to 35 MW heat duty.

Observation 2. Below the pinch, the point where $\mathrm{Q}_{C}$ equals zero is the limit for hot or cold stream $T_{S}$ to decrease. Further decrease in Ts leads to a penalty in $Q_{H}$.

It is observed that there exists a limit for $\mathrm{T}_{\mathrm{S}}$ to decrease for the hot or cold stream below the pinch, i.e., at the point of zero Qc. Any additional decrease in $\mathrm{T}_{\mathrm{S}}$ for hot or cold stream leads to a penalty of $\mathrm{Q}_{\mathrm{H}}$. Figure $6 \mathrm{a}, \mathrm{b}$ illustrate Observation 2 involving the disturbance scenario for HE4. It can be seen for the case that when Ts of stream $\mathrm{H} 2$ decrease, the enthalpy decrease exceeds the MER of cold stream C1, leading to a penalty of hot utility (see Figure $6 \mathrm{~b}$ ). This situation is also illustrated using the plus-minus principle shown in Figure 7. Moreover, decreasing $\mathrm{T}_{\mathrm{S}}$ for the hot stream at the pinch point or where the heat exchanger inlet has $\Delta \mathrm{T}=\Delta \mathrm{T}_{\min }$ also incurs a penalty at the other side stream. However, in this case, cold stream $\mathrm{C} 1$ does not end at the pinch and the difference of temperature between $\mathrm{T}_{\mathrm{S}, \mathrm{H} 2}$ and $\mathrm{T}_{\mathrm{t}, \mathrm{C} 1}$ is $25^{\circ} \mathrm{C}$, which is more than $\mathrm{T}_{\min }$.

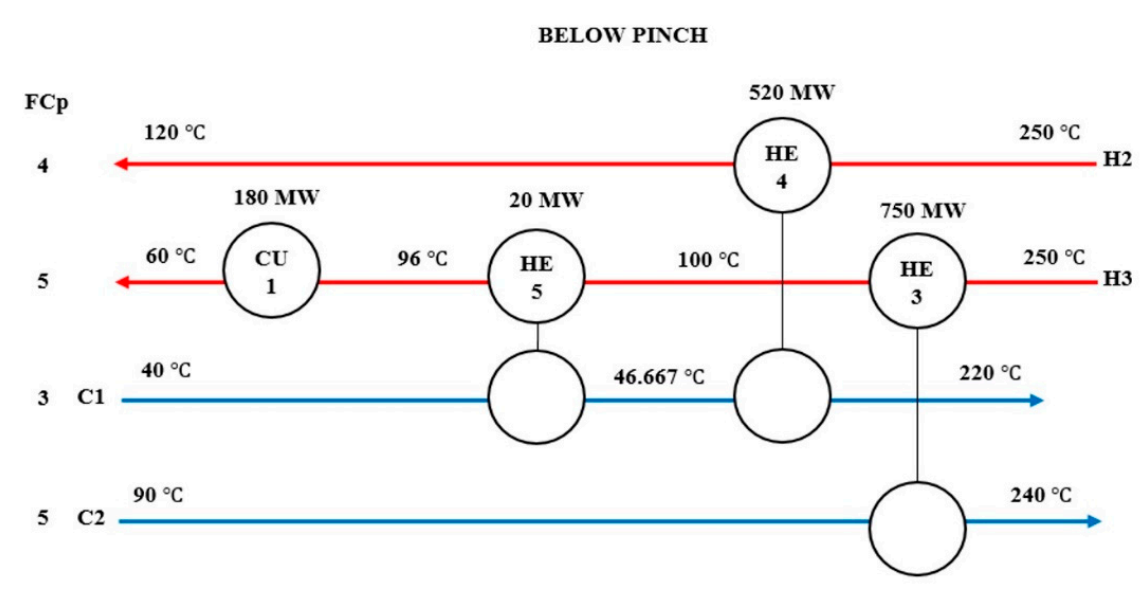

(a)

Figure 6. Cont. 
BELOW PINCH

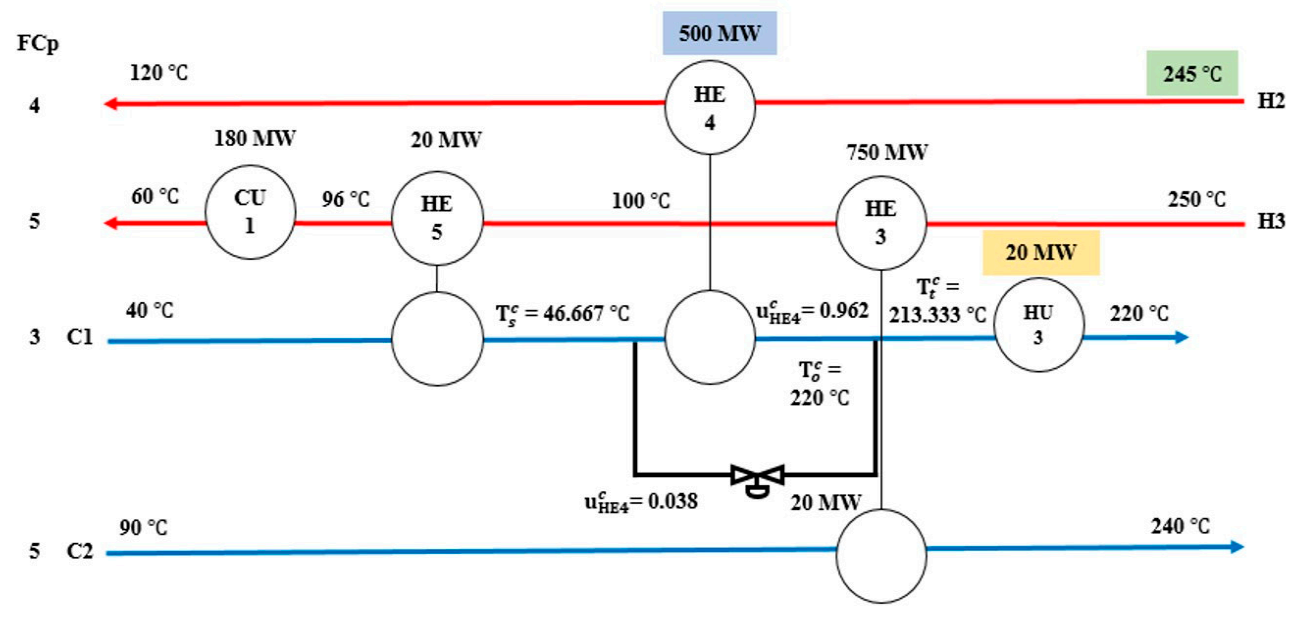

(b)

Figure 6. (a) HEN design with nominal $\mathrm{T}_{\mathrm{S}}$ for hot stream $\mathrm{H} 2$; (b) HEN design with $\mathrm{T}_{\mathrm{S}}$ decrease by $5{ }^{\circ} \mathrm{C}$ for hot stream $\mathrm{H} 2$.

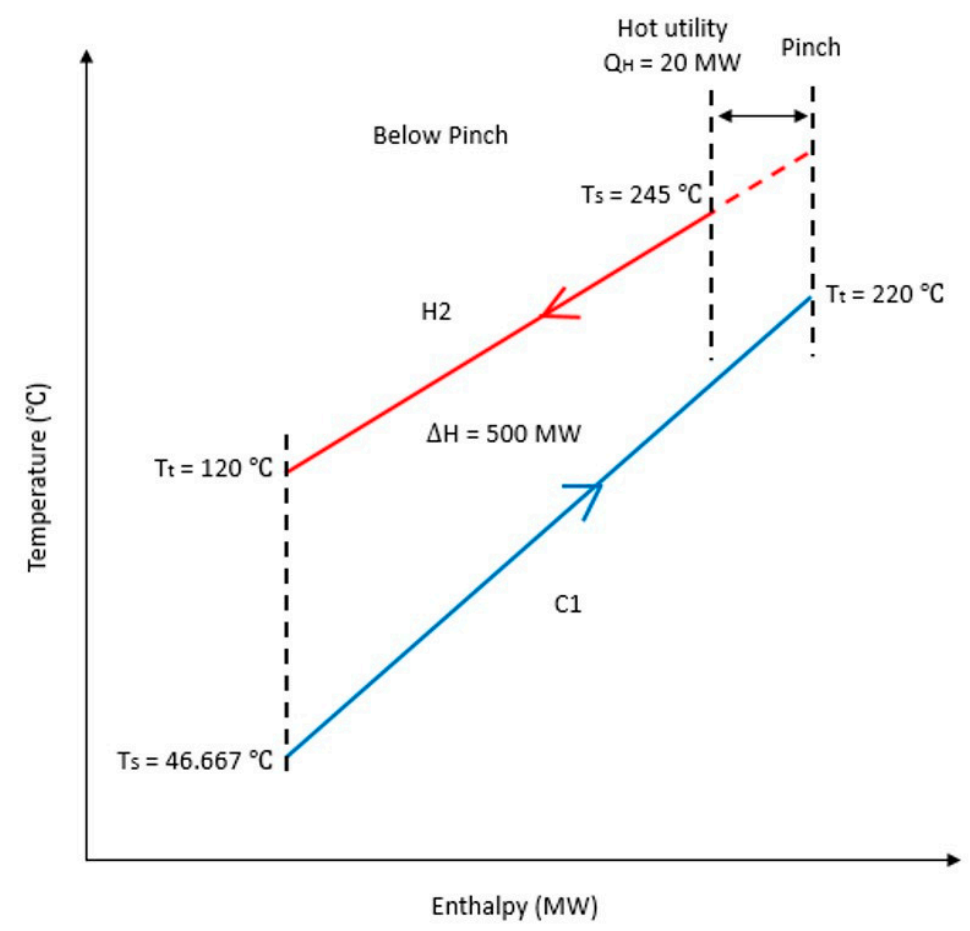

Figure 7. The plus-minus principle with decreasing $\mathrm{T}_{\mathrm{S}}$ by $5^{\circ} \mathrm{C}$ for hot stream $\mathrm{H} 2$ at HE4.

Observation 3. Increasing $T_{S}$ for a hot or cold stream below the pinch results in increasing $Q_{C}$.

Based on this third observation, increasing $\mathrm{T}_{\mathrm{S}}$ for a hot or cold stream located below the pinch causes $Q_{C}$ to increase. To illustrate this, consider an increase in $T_{S}$ for the cold stream $\mathrm{C} 1$ from $40{ }^{\circ} \mathrm{C}$ to $45^{\circ} \mathrm{C}$ due to a disturbance. Figure 4 shows that the increase in $\mathrm{T}_{\mathrm{S}}$ for the $\mathrm{C} 1$ resulted in the enthalpy for $\mathrm{C} 1$ decreasing by $15 \mathrm{MW}$. Since the Ts of stream $\mathrm{C} 1$ is located below the pinch, based on the plus-minus principle, the increase in Ts resulted in an increase in CU2 from 180 MW to 195 MW as shown in Figure 8. For this scenario, the bypass stream is selected as the manipulated variable as this deviation means the heat duty of heat exchanger HE5 is not high enough to keep the $T_{t}$ at $220^{\circ} \mathrm{C}$. Equation (2) is used to calculate the bypass fraction for the bypass placed on the cold streamside. In this scenario, supply temperature, $\mathrm{T}_{\mathrm{S}}^{\mathrm{c}}$ of HE5 at the cold stream side is $45^{\circ} \mathrm{C}$. The decreasing of the heat duty of 
HE 5 from $20 \mathrm{MW}$ to $5 \mathrm{MW}$ caused the target temperature of HE5 at cold stream side, $\mathrm{T}_{\mathrm{t}}^{\mathrm{c}}$ increased to $46.667{ }^{\circ} \mathrm{C}$. As the outlet temperature, $\mathrm{T}_{\mathrm{o}}^{\mathrm{c}}$ of HE5 with maximum duty at cold stream $\mathrm{C} 1$ is $56.667^{\circ} \mathrm{C}$, the bypass is placed on the cold stream side. Now the valve is opened at a bypass fraction, $\mathrm{u}_{\text {HE5 }}^{\mathrm{b}}$ of 0.857. The bypass is calculated by rearranging Equation (2). As the heat duty of heat exchanger HE5 is not high enough to achieve the final target temperature of $\mathrm{H} 3$, the cold utility of cooler $\mathrm{C} 2$ is increased to absorb the remaining heat.

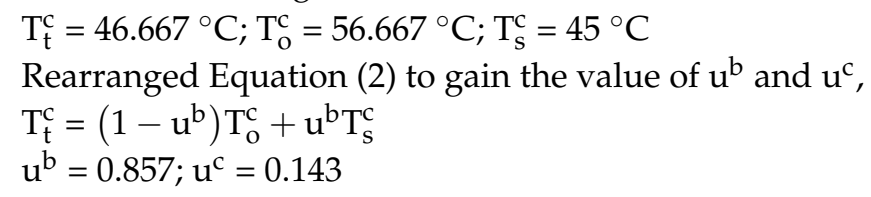

BELOW PINCH

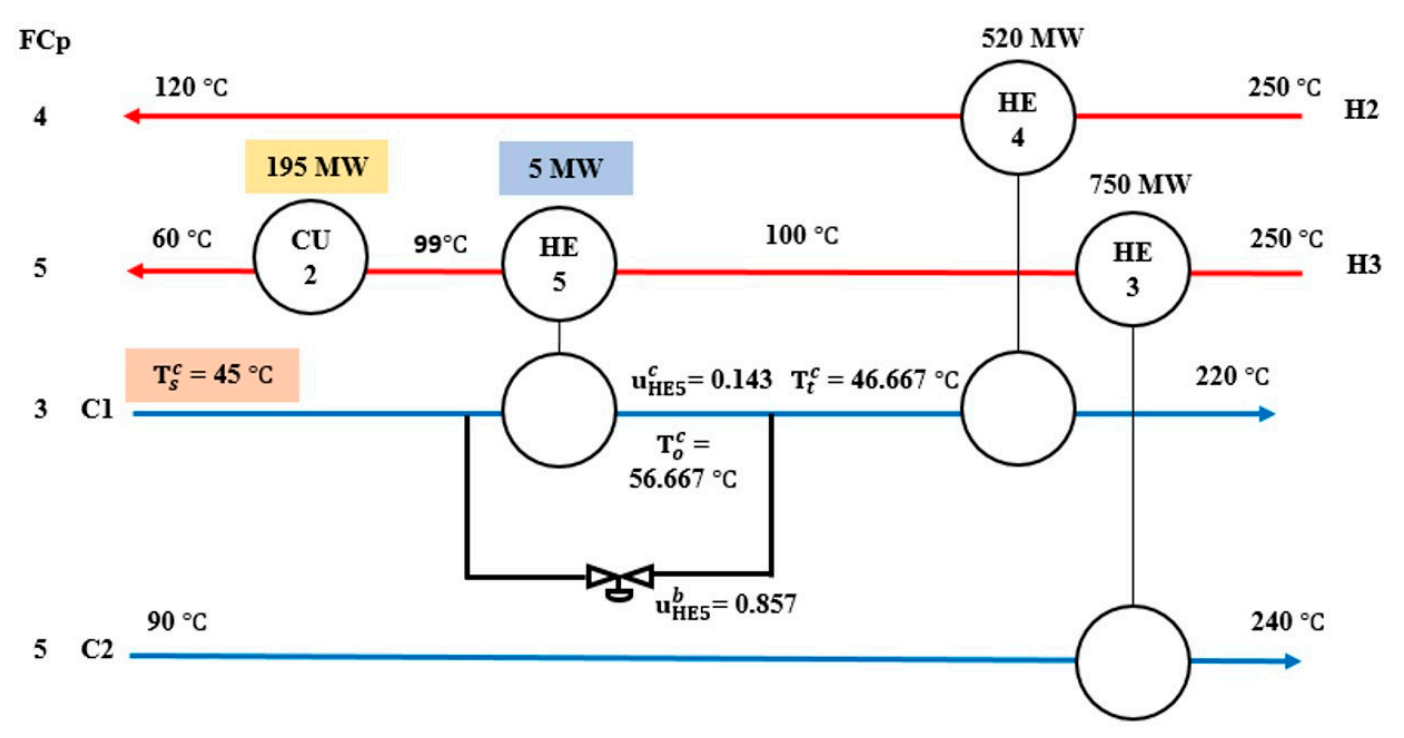

Figure 8. HEN design with $\mathrm{T}_{\mathrm{S}}$ increased for cold stream below the pinch.

Observation 4. Below the pinch, size the heat exchanger to achieve the maximum energy recovery target when $\mathrm{T}_{\mathrm{S}}$ decreases, and the cooler to achieve the higher utility when Ts increases.

Observation 4 states that the heat exchanger size below the pinch should be designed to achieve the maximum energy recovery when $T_{S}$ decreases and the cooler size should be designed to achieve the higher utility when Ts increases. Previously, the impact of the increase or decrease of Ts on cold stream $\mathrm{C} 1$ was shown. In the case of decreasing Ts, more heat is allowed to be exchanged. It is preferable to design HE5 with a bigger area to accommodate up to at 35 MW heat duty instead of 20 MW heat duty for the nominal case. CU2 cold utility should also be designed with the duty of $195 \mathrm{MW}$ instead of the nominal case with the duty of $180 \mathrm{MW}$ in order to absorb the remaining heat when Ts increases. Figure $9 \mathrm{a}-\mathrm{c}$ illustrate this situation by using the plus-minus principle. The bypass stream is used to control the duty of HE5 during the disturbances as shown in Figure 10a-c, while the CU2 cold utility is used to absorb the remaining heat.

Above the pinch:

Observation 5. Increasing $T_{S}$ for a hot or cold stream above the pinch results in decreasing $Q_{H}$.

Observation 5 states that, increasing $T_{S}$ for hot or cold stream located below the pinch results in $\mathrm{Q}_{\mathrm{H}}$ decreasing. For example, $\mathrm{T}_{\mathrm{S}}$ of hot stream $\mathrm{H} 1$ increases from $310^{\circ} \mathrm{C}$ to $315^{\circ} \mathrm{C}$. As shown in Figure 3, the increasing $\mathrm{T}_{\mathrm{S}}$ on hot stream $\mathrm{H} 1$ increases $\mathrm{H} 1$ enthalpy by $15 \mathrm{MW}$. Based on the plus-minus principle, since stream H1 is located above the pinch, it can be used to recover more energy. This would result in a reduction of HU1 hot utility from $130 \mathrm{MW}$ to $115 \mathrm{MW}$, which is desirable (as shown in Figure 11. In order to control the target temperature of stream $\mathrm{H} 1$ at $270{ }^{\circ} \mathrm{C}$, the $\mathrm{H} 1$ flowrate entering HE2 is selected as a manipulated variable. The duty of HE2 is increased from 120 MW to $135 \mathrm{MW}$ to 
allow more heat to be exchanged. In order to attain it, HE2 should be designed with a bigger area to accommodate up to 135 MW heat duty.

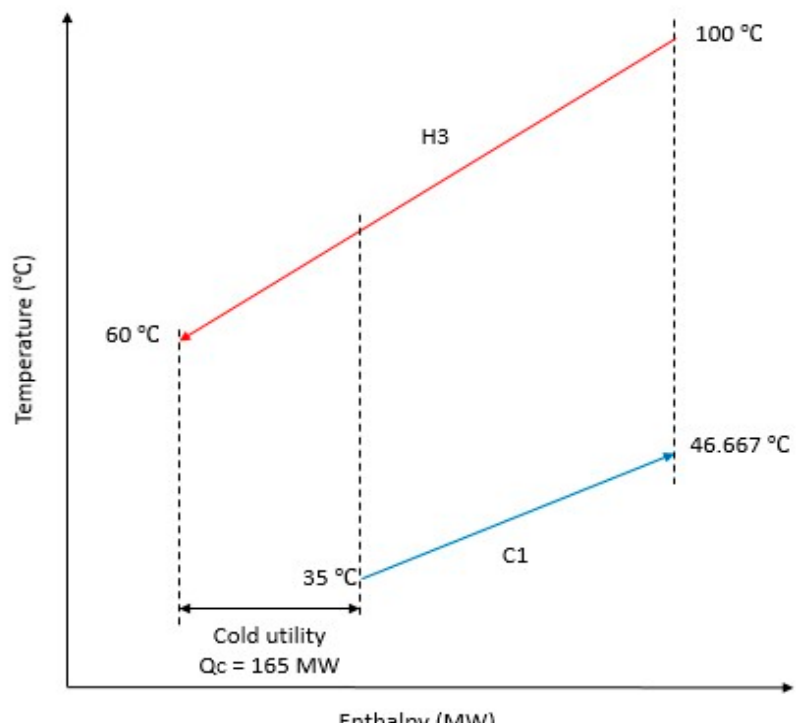

(a)

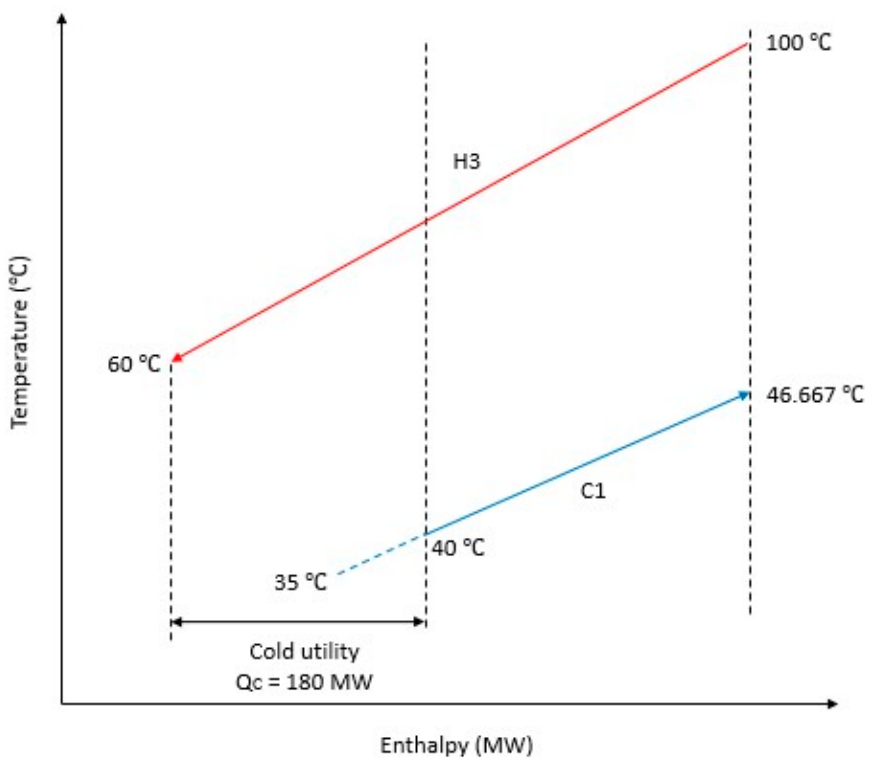

(b)

Figure 9. Cont. 


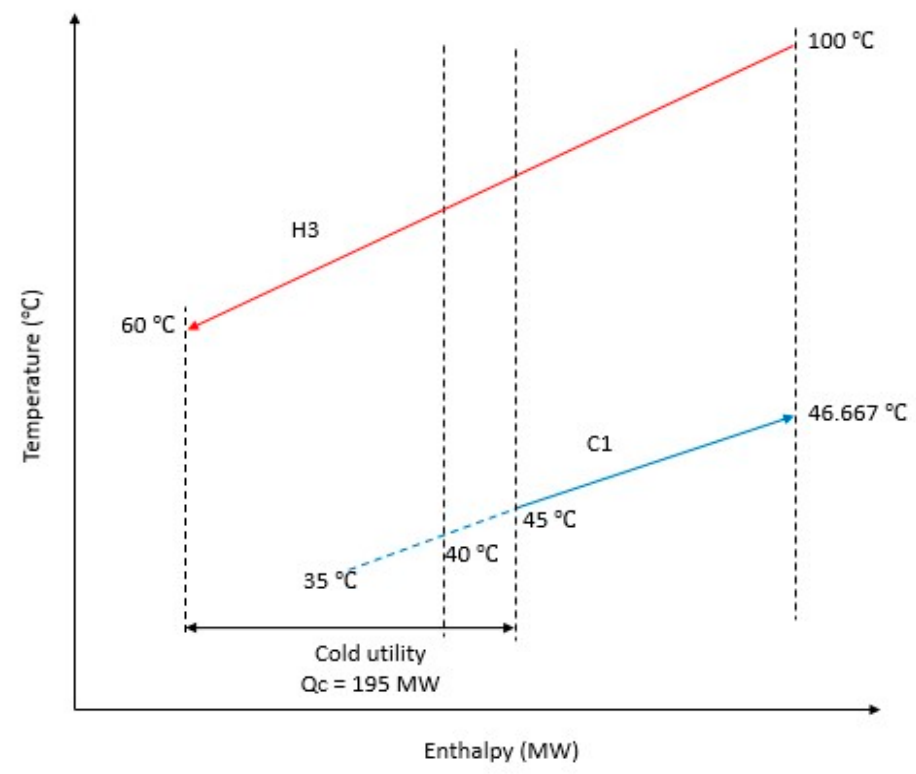

(c)

Figure 9. (a) The plus-minus principle with $\mathrm{T}_{\mathrm{S}}$ decreased by $5{ }^{\circ} \mathrm{C}$ for $\mathrm{C} 1$; (b) the plus-minus principle of nominal $\mathrm{T}_{\mathrm{S}}$ for $\mathrm{C} 1$; (c) The plus-minus principle with $\mathrm{T}_{\mathrm{S}}$ increased by $5{ }^{\circ} \mathrm{C}$ for $\mathrm{C} 1$.

BELOW PINCH

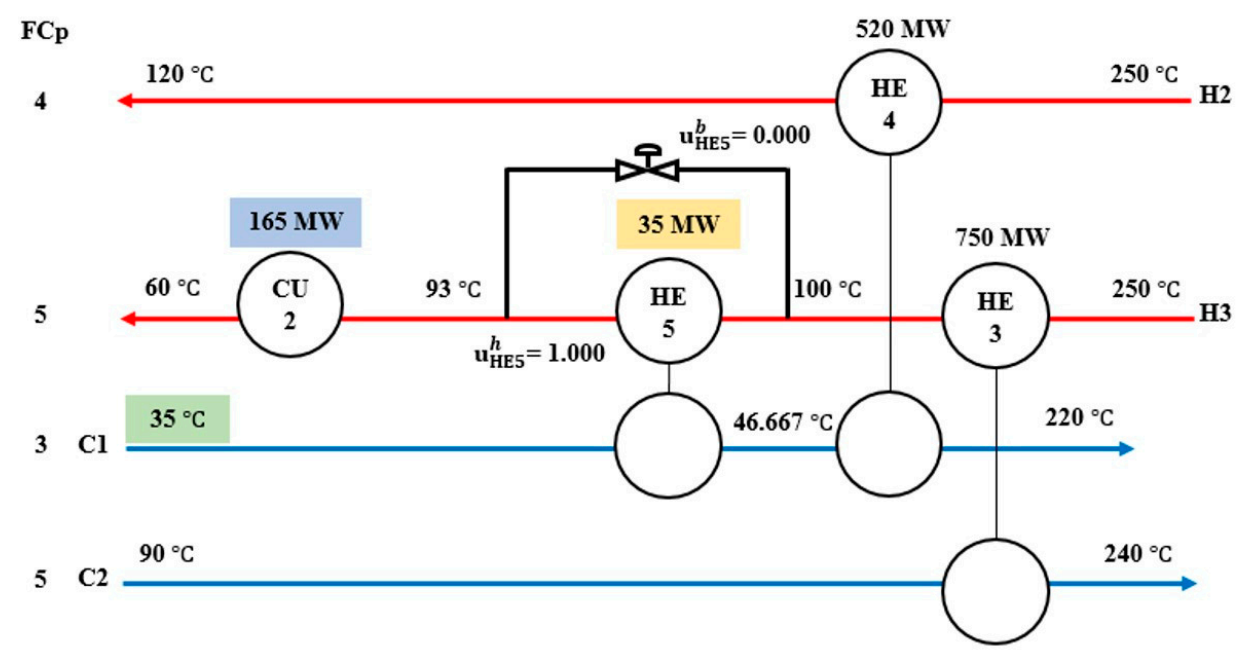

(a)

Figure 10. Cont. 


\section{BELOW PINCH}

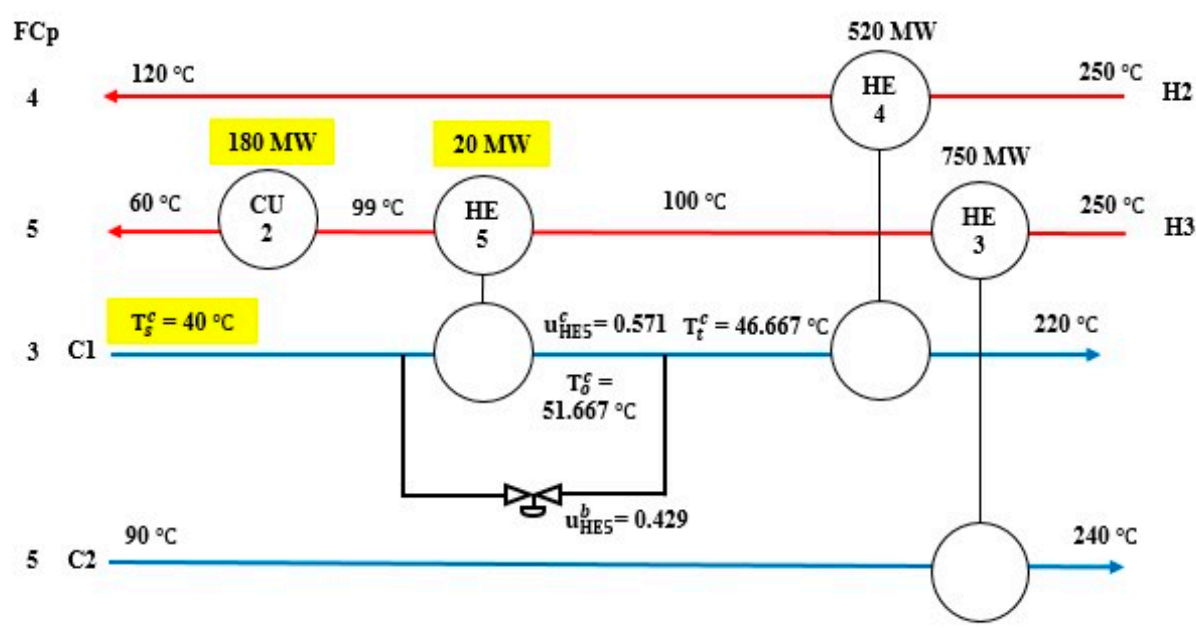

(b)

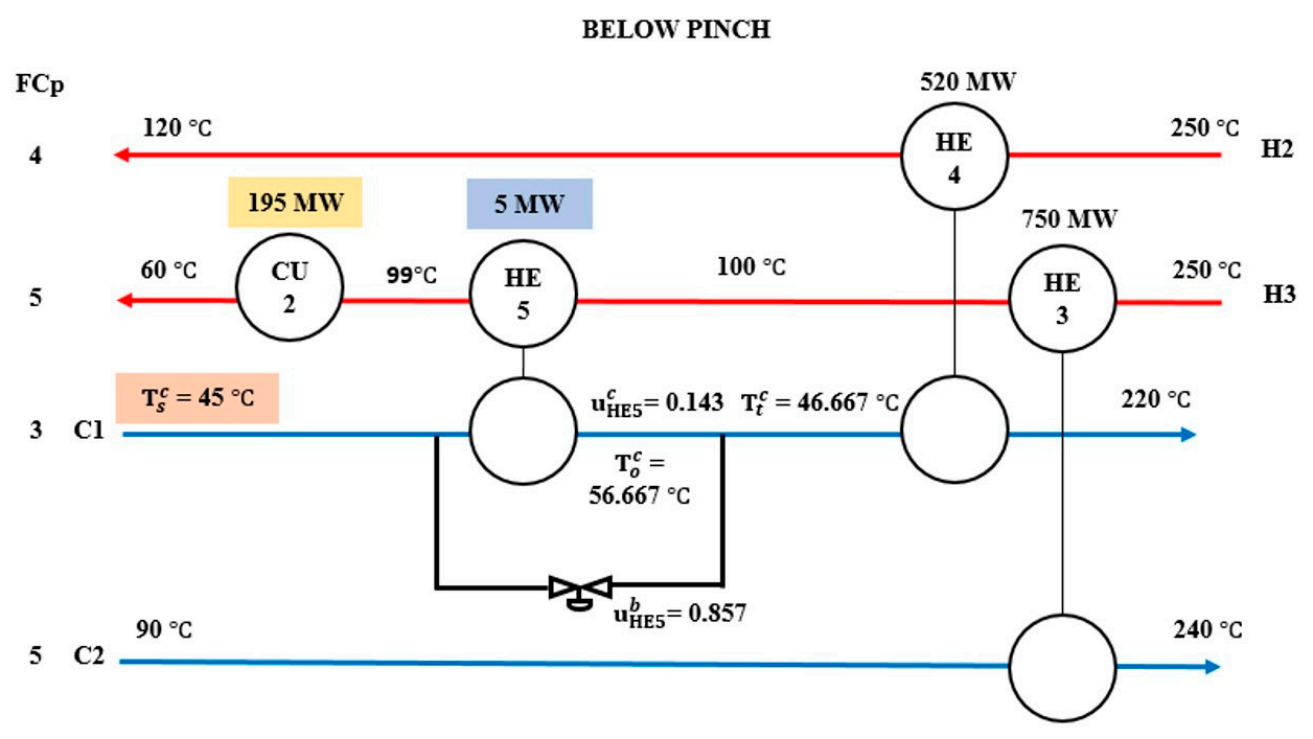

(c)

Figure 10. (a) HEN design with $\mathrm{T}_{\mathrm{S}}$ decreased by $5{ }^{\circ} \mathrm{C}$ for $\mathrm{C} 1$. HE5 is designed with a bigger area to accommodate up to $35 \mathrm{MW}$ heat duty; (b) HEN design with nominal $\mathrm{T}_{\mathrm{S}}$ for $\mathrm{C} 1$. HE5 is designed with a bigger area and heat duty at $20 \mathrm{MW}$; (c) HEN design with $\mathrm{T}_{\mathrm{S}}$ increased by $5{ }^{\circ} \mathrm{C}$ for $\mathrm{C} 1$. HE5 is designed with a bigger size and heat duty at $5 \mathrm{MW}$.

Observation 6. Above the pinch, the point where $\mathrm{Q}_{\mathrm{H}}$ equals zero is the limit for hot or cold stream $\mathrm{T}_{\mathrm{S}}$ to increase. Further increases in $\mathrm{T}_{\mathrm{S}}$ lead to a penalty of $\mathrm{Q}_{\mathrm{C}}$.

As explained in Observation 2, the same situation can also occur above the pinch. There is a limit for $T_{S}$ to increase for hot or cold streams above the pinch, i.e., at the point of zero $Q_{H}$. Further increases in $T_{S}$ for the hot or cold stream lead to a penalty of $Q_{C}$. Besides that, increasing $T_{S}$ for the hot stream at the pinch or where the heat exchanger inlet has $\Delta \mathrm{T}=\Delta \mathrm{T}_{\min }$ also leads to a penalty at the other side stream. Figure 12 shows that $\mathrm{T}_{\mathrm{S}}$ increases for cold stream $\mathrm{C} 3$ from $240{ }^{\circ} \mathrm{C}$ to $245^{\circ} \mathrm{C}$. The nominal value of $\mathrm{T}_{\mathrm{S}}$ on cold stream $\mathrm{C} 3$ and the outlet temperature of HE1 on the hot stream side is at the pinch temperature. The $\Delta \mathrm{T}$ of HE1 decrease to $5^{\circ} \mathrm{C}$, which is less than the original $\Delta \mathrm{T}_{\min }$ of $10{ }^{\circ} \mathrm{C}$. This cause the enthalpy of cold stream C3 reduced to $385 \mathrm{MW}$. HE1 with the duty of $100 \mathrm{MW}$ 
led the hot utility HU2 minimised to $285 \mathrm{MW}$ (see Figure 12). This situation is also illustrated by the plus-minus principle shown in Figure 13a,b. Figure 13a shows the nominal temperature of stream C3 matching with stream $\mathrm{H} 3$ with $\Delta \mathrm{T}_{\min }$ of $10^{\circ} \mathrm{C}$. Figure $13 \mathrm{~b}$ shows that, increasing of $\mathrm{T}_{\mathrm{S}}$ on cold stream results in $\Delta \mathrm{T}$ less than $\Delta \mathrm{T}_{\min }$.

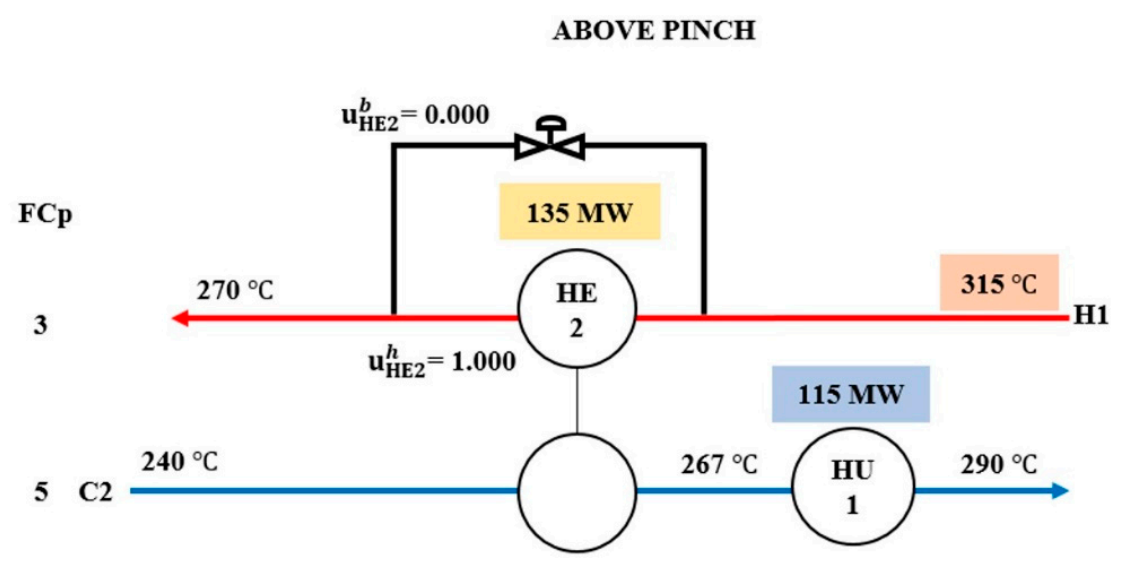

Figure 11. HEN design with increasing $\mathrm{T}_{\mathrm{S}}$ for the hot stream $\mathrm{H} 1$ above the pinch.

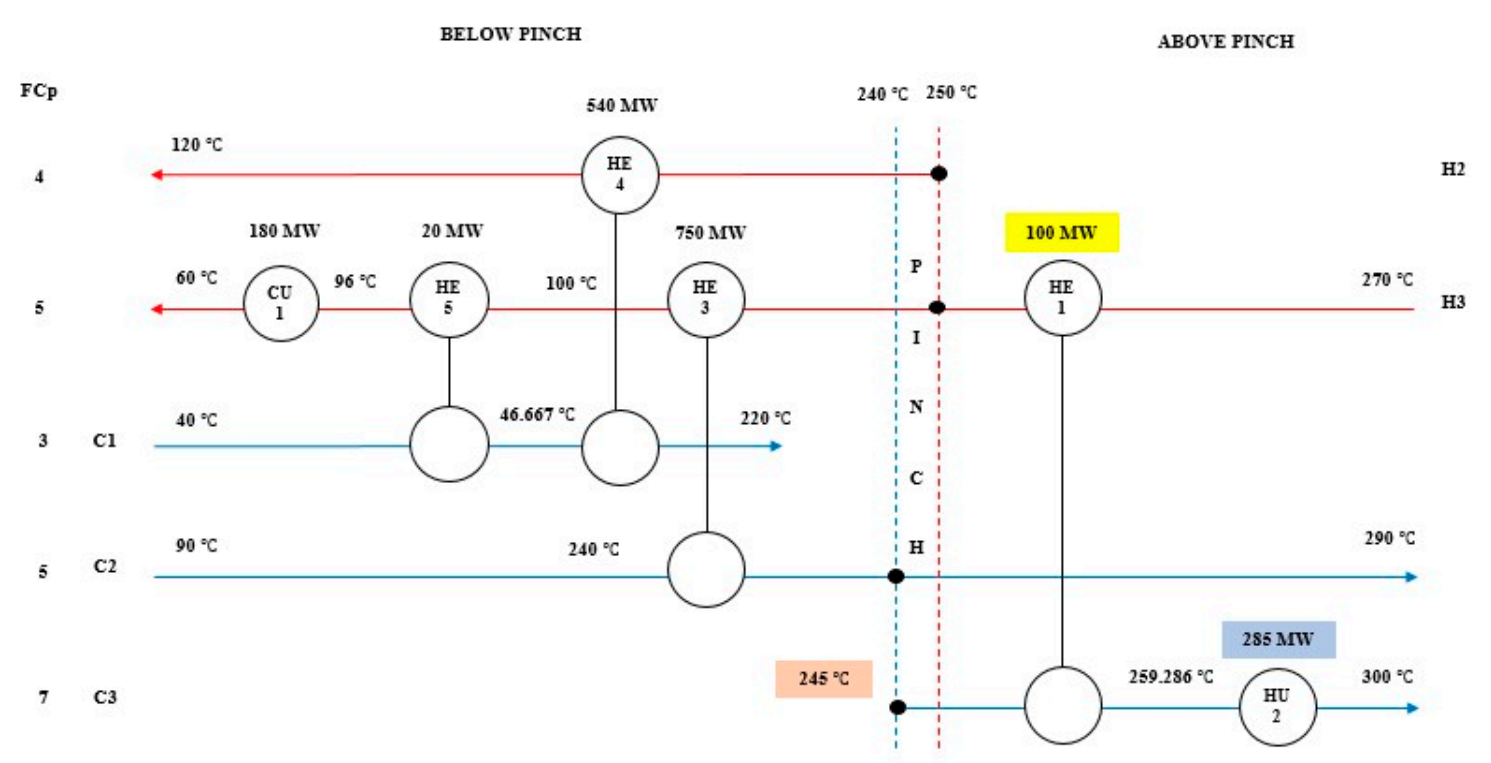

Figure 12. HEN design with increasing $\mathrm{T}_{\mathrm{S}}$ for cold stream at the pinch.

Observation 7. Decreasing $T_{S}$ for a hot or cold stream above the pinch results in increasing $Q_{H}$.

As stated in observation 7 , decreasing $\mathrm{T}_{\mathrm{S}}$ for hot or cold stream located above the pinch causes $\mathrm{Q}_{\mathrm{H}}$ to increase. To illustrate this, consider a decrease in $\mathrm{T}_{\mathrm{S}}$ for the hot stream $\mathrm{H} 1$ from $310^{\circ} \mathrm{C}$ to $305^{\circ} \mathrm{C}$. Figure 3 shows that the decrease in $\mathrm{T}_{\mathrm{S}}$ for the $\mathrm{H} 1$ resulted in the enthalpy for $\mathrm{H} 1$ to decrease by $15 \mathrm{MW}$. Since the $\mathrm{T}_{\mathrm{S}}$ of stream $\mathrm{H} 1$ is located above the pinch, based on the plus-minus principle, the decrease in $\mathrm{T}_{\mathrm{S}}$ resulted in an increase in hot utility HU1 from $130 \mathrm{MW}$ to $145 \mathrm{MW}$ as shown in Figure 14. For this scenario, the bypass stream is selected as a manipulated variable as this deviation means the heat duty of heat exchanger HE2 is not high enough to keep the target temperature at $270{ }^{\circ} \mathrm{C}$. Equation (1) is used to calculate the bypass fraction for the bypass placed on the hot streamside. In this scenario, the supply temperature, $\mathrm{T}_{\mathrm{s}}^{\mathrm{h}}$ of HE2 at the hot stream side is $305^{\circ} \mathrm{C}$. The decrease in heat duty of HE2 from $120 \mathrm{MW}$ to $105 \mathrm{MW}$ caused the target temperature of heat exchanger HE2 at hot stream side, $\mathrm{T}_{\mathrm{t}}^{\mathrm{h}}$ to decrease to $270{ }^{\circ} \mathrm{C}$. As the outlet temperature, $\mathrm{T}_{\mathrm{o}}^{\mathrm{h}}$ of HE2 with maximum duty at hot stream H1 is $260^{\circ} \mathrm{C}$, the bypass is placed on the hot stream side. Then, the valve is opened at a bypass fraction, 
$\mathrm{u}_{\mathrm{HE} 2}^{\mathrm{b}}$ of 0.286 . The bypass is calculated by rearranging Equation (1). As the heat duty of heat exchanger HE2 is not high enough to achieve the final target temperature of $\mathrm{C} 2$, the hot utility of heater HU1 is increased in order to satisfy the remaining heat.

$\mathrm{T}_{\mathrm{t}}^{\mathrm{h}}=270{ }^{\circ} \mathrm{C} ; \mathrm{T}_{\mathrm{o}}^{\mathrm{h}}=260^{\circ} \mathrm{C} ; \mathrm{T}_{\mathrm{s}}^{\mathrm{h}}=305^{\circ} \mathrm{C}$

Rearranged Equation (1) to gain the value of $\mathrm{u}^{\mathrm{b}}$ and $\mathrm{u}^{\mathrm{c}}$,

$\mathrm{T}_{\mathrm{t}}^{\mathrm{h}}=\left(1-\mathrm{u}^{\mathrm{b}}\right) \mathrm{T}_{\mathrm{o}}^{\mathrm{h}}+\mathrm{u}^{\mathrm{b}} \mathrm{T}_{\mathrm{s}}^{\mathrm{h}}$

$\mathrm{u}^{\mathrm{b}}=0.222 ; \mathrm{u}^{\mathrm{h}}=0.778$

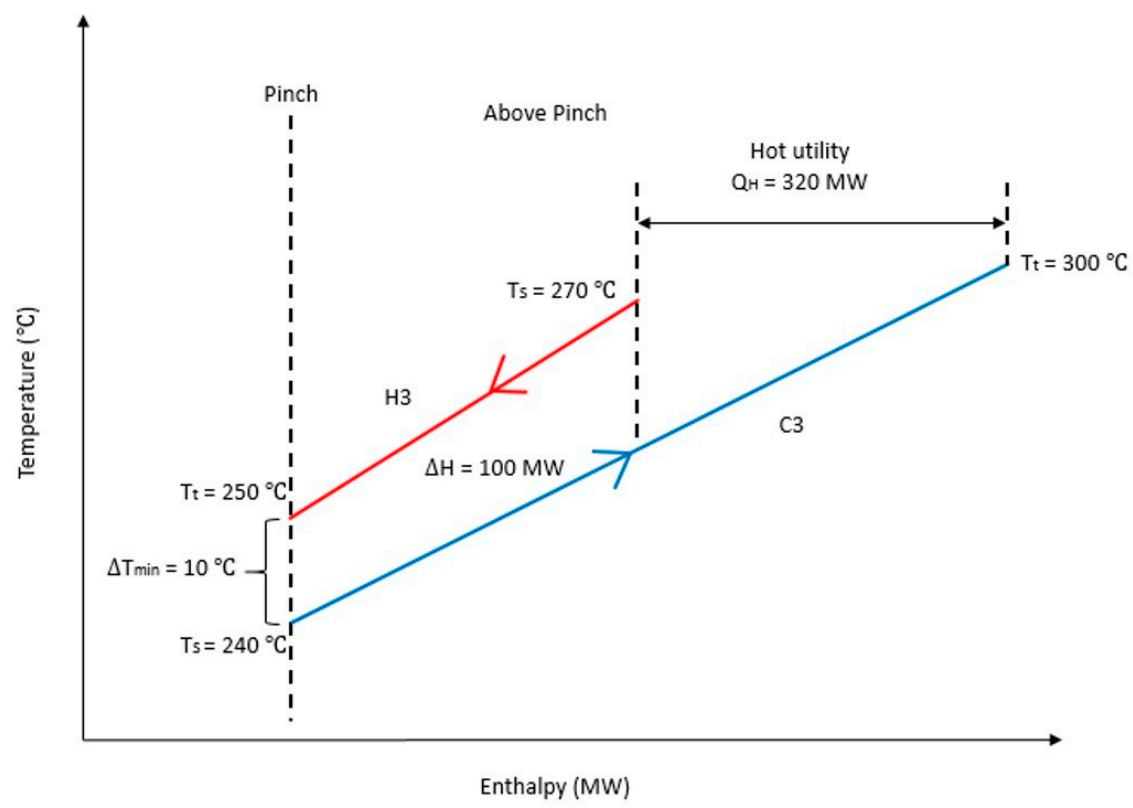

(a)

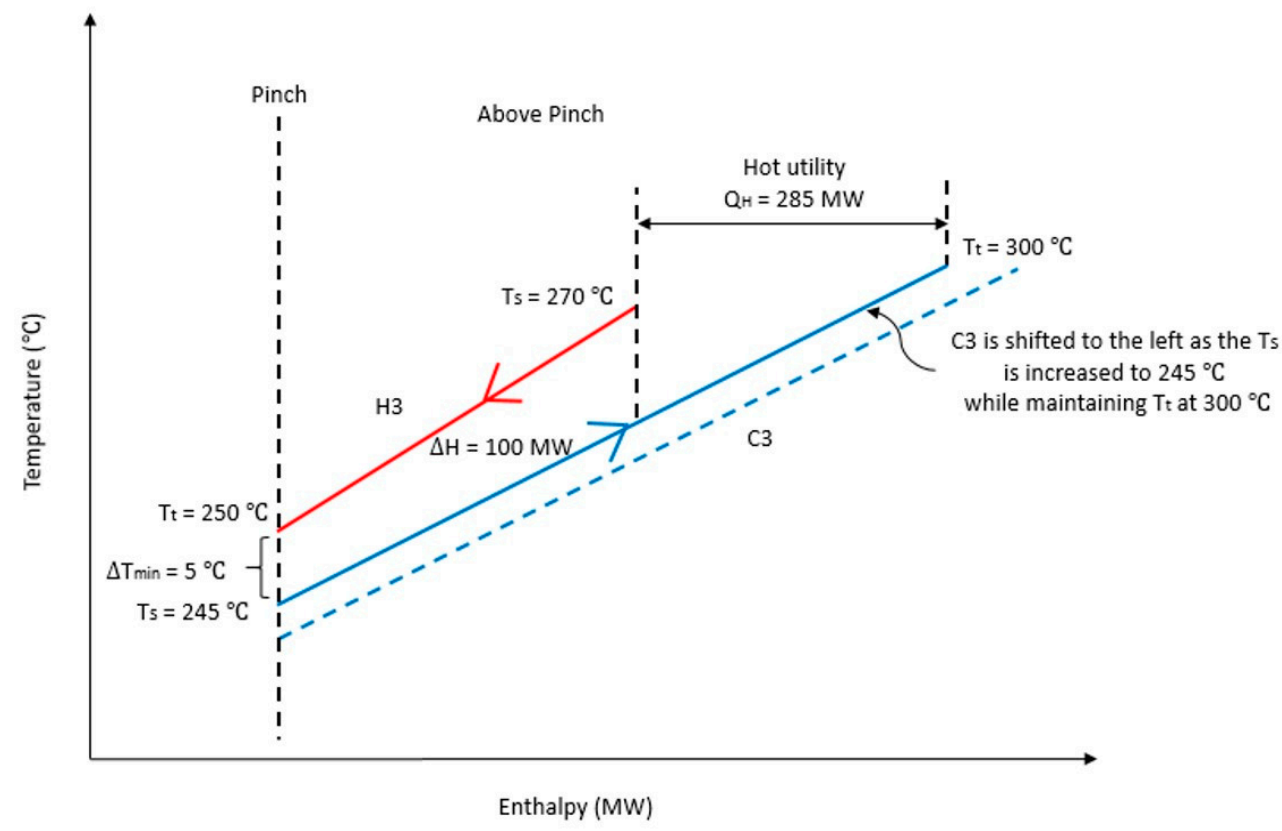

(b)

Figure 13. (a) The plus-minus principle of nominal $\mathrm{T}_{\mathrm{S}}$ for cold stream at the pinch with $\mathrm{T}_{\min }=10^{\circ} \mathrm{C}$; (b) The plus-minus principle of infeasible matching with increasing $\mathrm{T}_{\mathrm{S}}$ for the cold stream at the pinch. 
ABOVE PINCH

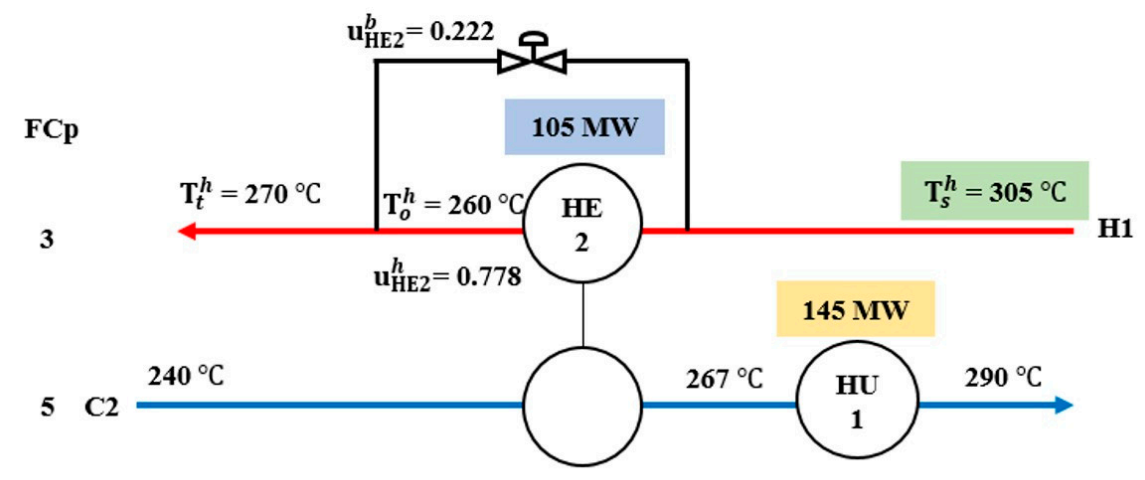

Figure 14. HEN design with $\mathrm{T}_{\mathrm{S}}$ decreased for hot stream $\mathrm{H} 1$ above the pinch.

Observation 8. Above the pinch, size the heat exchanger to achieve the maximum energy recovery when $T_{S}$ increase, and the heater to achieve the minimum utility when $T_{S}$ decrease.

Observation 8 states that the heat exchanger size above the pinch should be designed to achieve the maximum energy recovery when $T_{S}$ increases, and the heater size should be designed to achieve the higher utility when $T_{S}$ decreases. Previously, the impact of increase or decrease in Ts on hot stream $\mathrm{H} 1$ was shown. In the case of increasing Ts, more heat is allowed to be exchanged. It is preferable to design HE2 with a bigger area to accommodate up to $135 \mathrm{MW}$ heat duty instead of $120 \mathrm{MW}$ for the nominal case. HU1 hot utility should also be designed with the bigger capacity of 145 MW heat duty instead of the nominal case of $130 \mathrm{MW}$, in order to cater for the remaining heat when $\mathrm{T}_{\mathrm{S}}$ decreases. Figure 15a-c illustrate this situation by using the plus-minus principle. The bypass stream is used to control the duty of HE2 when a disturbance occurs as shown in Figure 16a-c, while HU1 hot utility is used is to satisfy the remaining heat.

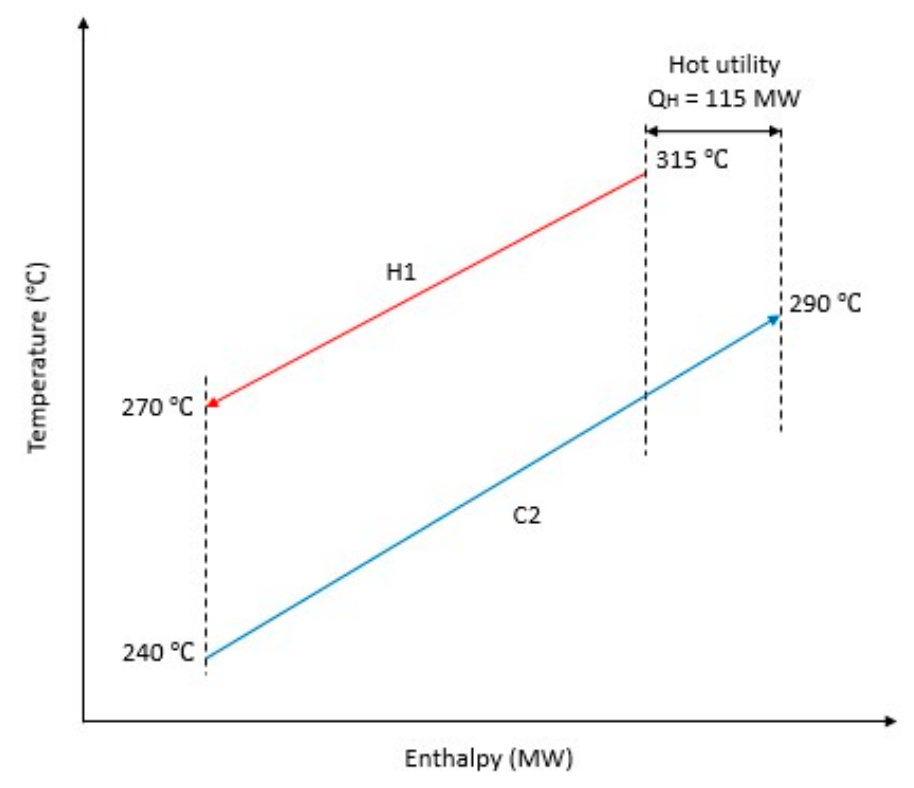

(a)

Figure 15. Cont. 


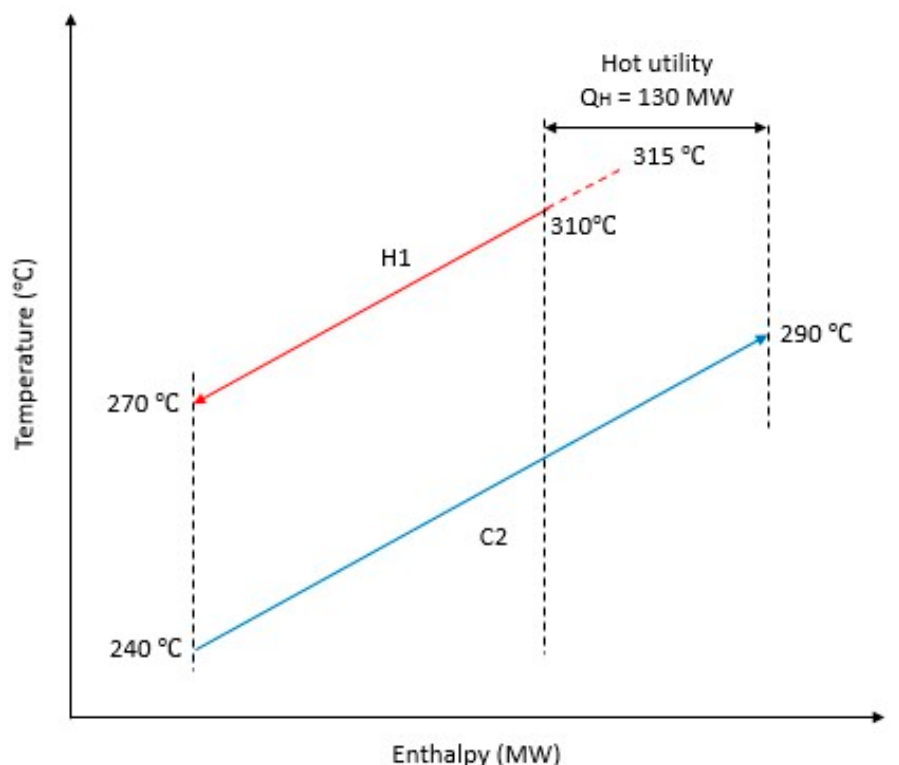

(b)

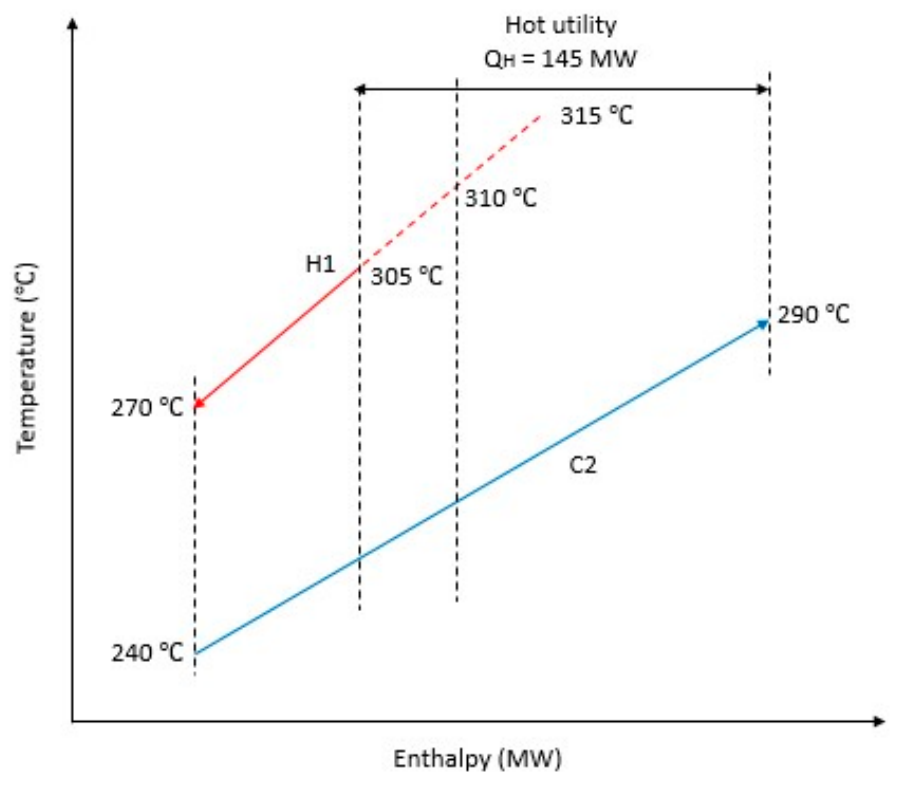

(c)

Figure 15. (a) The plus-minus principle with increasing $\mathrm{T}_{\mathrm{S}}$ by $5{ }^{\circ} \mathrm{C}$ for $\mathrm{H1}$; (b) The PLUS-MINUS principle for nominal $\mathrm{T}_{\mathrm{S}}$ for $\mathrm{H} 1$ considering maximum size of $\mathrm{HE}$ and a bypass; (c) The plus-minus principle with decreasing $\mathrm{T}_{\mathrm{S}}$ by $5{ }^{\circ} \mathrm{C}$ for $\mathrm{H} 1$ considering maximum size of $\mathrm{HE}$ and a bypass. 


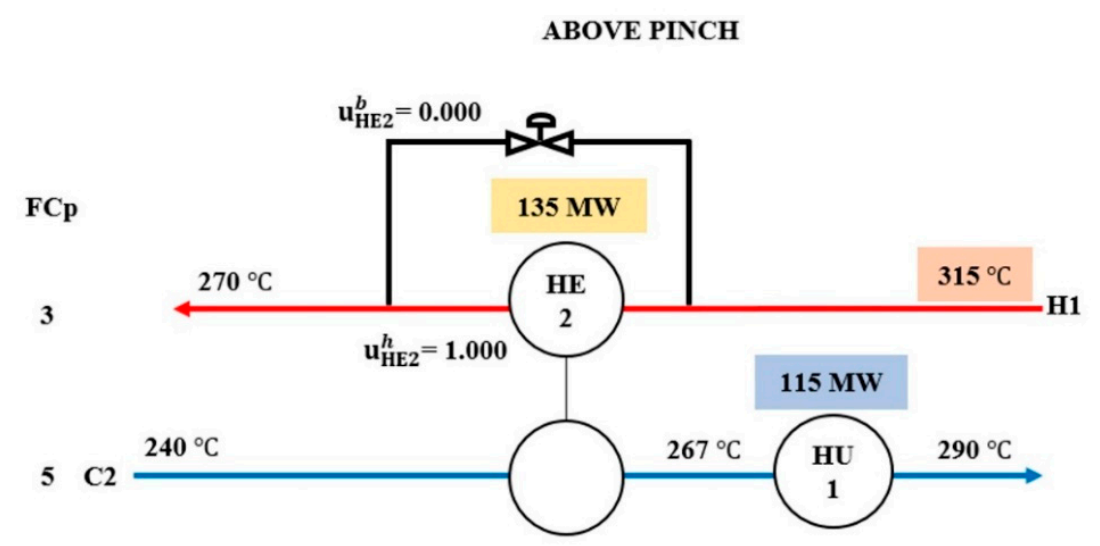

(a)

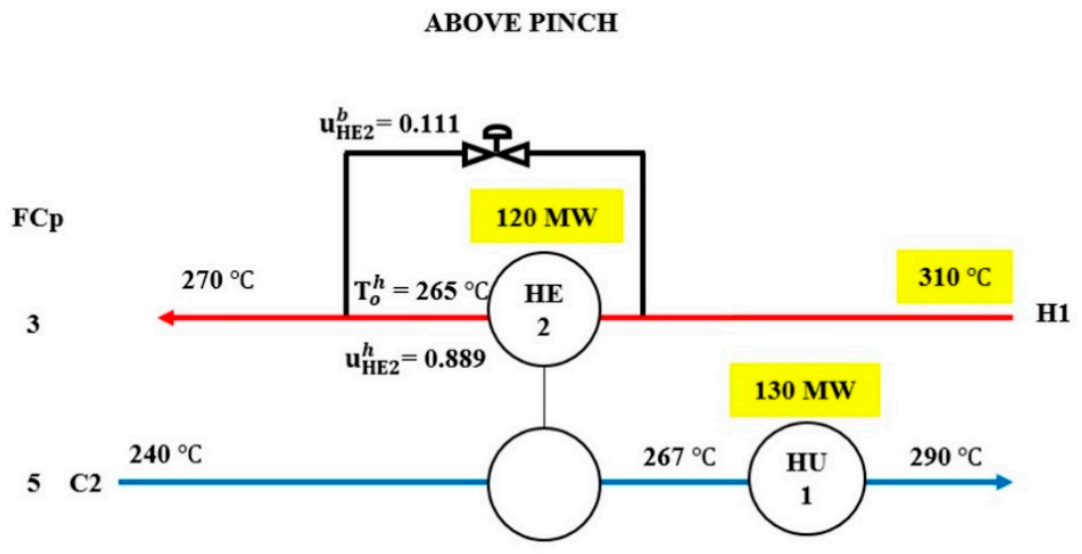

(b)

ABOVE PINCH

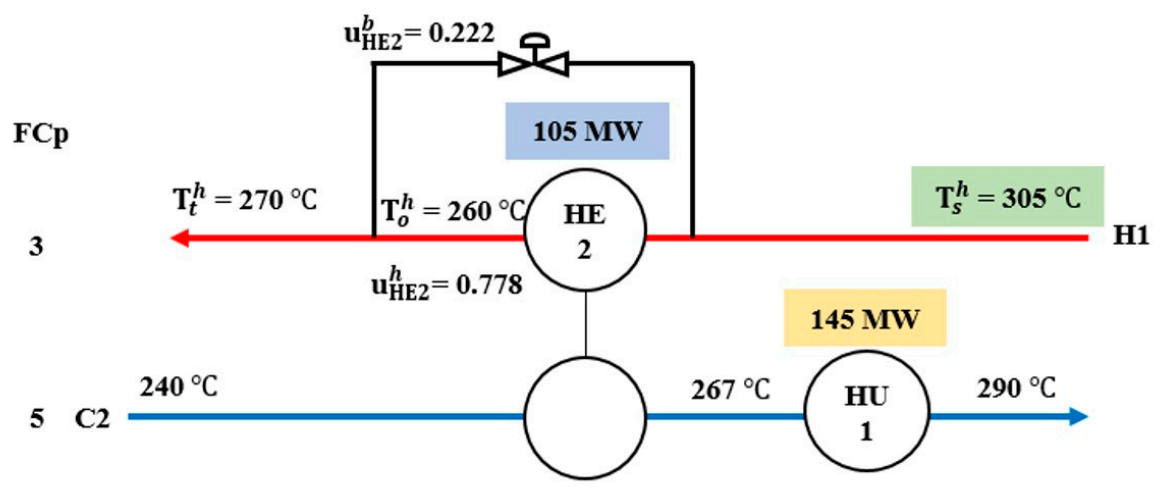

(c)

Figure 16. (a) HEN design with $\mathrm{T}_{\mathrm{S}}$ increase by $5{ }^{\circ} \mathrm{C}$ for $\mathrm{H} 1$. HE2 is designed with a bigger area to accommodate up to $135 \mathrm{MW}$ heat duty; (b) HEN design for nominal $\mathrm{T}_{\mathrm{S}}$ for H1. HE2 is designed with a bigger area and $120 \mathrm{MW}$ heat duty; (c) HEN design with $\mathrm{T}_{\mathrm{S}}$ decrease by $5{ }^{\circ} \mathrm{C}$ for $\mathrm{H} 1$. HE2 is designed with bigger area and 105 MW heat duty.

Based on Observations 1 to 8, two heuristics are proposed for HEN design cases above and below the pinch to allow for flexibility and controllability in achieving maximum energy recovery: 
(1) Heuristic 1: Bypass placement to cater for disturbances in MER HEN

a. A bypass should be placed at the disturbed stream if the $T_{S}$ value increases or decreases on either above or below the pinch and if $\Delta \mathrm{T} \neq 0$.

b. A bypass should be placed on the other side of the disturbed stream if the $\mathrm{T}_{\mathrm{S}}$ value is touching the pinch point, and if $\Delta \mathrm{T}=0$ or the enthalpy is less than the enthalpy of another side of the disturbed stream.

(2) Heuristic 2: Heat exchanger sizing to cater for disturbances in MER HEN

a. Size a heat exchanger to cater to the highest amount of energy to be exchanged, considering all disturbances scenario.

b. Size a utility heat exchanger to cater to the highest amount of utility needed, considering all disturbances scenario.

After all the heuristics have been applied to the HEN design to cater for all the possible scenarios, there are some issues that must be checked:

(1) After adjusting heat exchanger duties, temperature feasibility test should be done for all the affected streams. If temperature infeasibility occurs, designers should consider redistributing the duty to the utilities.

(2) The bypass fraction should be calculated for all possible cases considering the biggest heat exchanger size.

Table 2 summarises the effects of cold and hot streams' supply temperature disturbances on hot and cold utilities as explained in the heuristics. 
Table 2. Summary of cold and hot stream supply temperature disturbances on hot and cold utilities.

\begin{tabular}{|c|c|c|c|c|c|c|}
\hline & $\mathbf{T}_{\mathrm{S}, \text { hot }}$ & Effect on $Q_{C}$ & Effect on $Q_{H}$ & $\mathrm{~T}_{\mathrm{S}, \text { cold }}$ & Effect on $Q_{C}$ & Effect on $Q_{H}$ \\
\hline \multirow[t]{3}{*}{ Below Pinch } & $\begin{array}{l}\text { Decrease but HE } \Delta \mathrm{T} \text { still } \\
\geq \Delta \mathrm{T}_{\min } \text { or } \Delta \mathrm{T}<\Delta \mathrm{T}_{\min } \\
\quad(\text { Observation } 1)\end{array}$ & Decrease & $\begin{array}{l}\text { None unless the } \\
\text { reduction of the hot } \\
\text { enthalpy is more than the } \\
\text { available cold stream for } \\
\text { MER (Observation 2) }\end{array}$ & Decrease (Observation 1) & Decrease & None \\
\hline & $\begin{array}{l}\text { Decrease but HE } \Delta \mathrm{T}=0 \\
\quad \text { (Observation } 2)\end{array}$ & Decrease & Increase & - & - & - \\
\hline & $\begin{array}{c}\text { Increase } \\
\text { (Observation 3) }\end{array}$ & Increase & None & Increase (Observation 3) & Increase & None \\
\hline \multirow[t]{3}{*}{ Above Pinch } & $\begin{array}{c}\text { Increase } \\
\text { (Observation 5) }\end{array}$ & None & Decrease & $\begin{array}{l}\text { Increase but HE } \Delta \mathrm{T} \text { still } \\
\geq \Delta \mathrm{T}_{\min } \text { or } \Delta \mathrm{T}<\Delta \mathrm{T}_{\min } \\
\quad \text { (Observation } 5)\end{array}$ & $\begin{array}{l}\text { None unless the reduction } \\
\text { of the cold enthalpy is } \\
\text { more than the available hot } \\
\text { stream for MER } \\
\text { (Observation 6) }\end{array}$ & Decrease \\
\hline & - & - & - & $\begin{array}{l}\text { Increase but } \mathrm{HE} \Delta \mathrm{T}=0 \\
\quad(\text { Observation } 6)\end{array}$ & Increase & Decrease \\
\hline & $\begin{array}{c}\text { Decrease } \\
\text { (Observation 7) }\end{array}$ & None & Increase & Decrease (Observation 7) & None & Increase \\
\hline
\end{tabular}




\section{Final Sizing and Bypass Design for MER HEN with Disturbance on $T_{S}$}

The heuristics proposed are applied for designing a HEN that is flexible to disturbances. Analysis of the effect of disturbances on each stream in the HEN is summarised in Table 3. It is shown that disturbances can cause either positive or negative impacts on the $Q_{H}$ and $Q_{C}$ of HEN. The bypass fraction is determined based on the heuristics proposed. Figure 17 shows the final HEN with the bypass placed. Each stream applied different heuristics according to the scenario described previously.

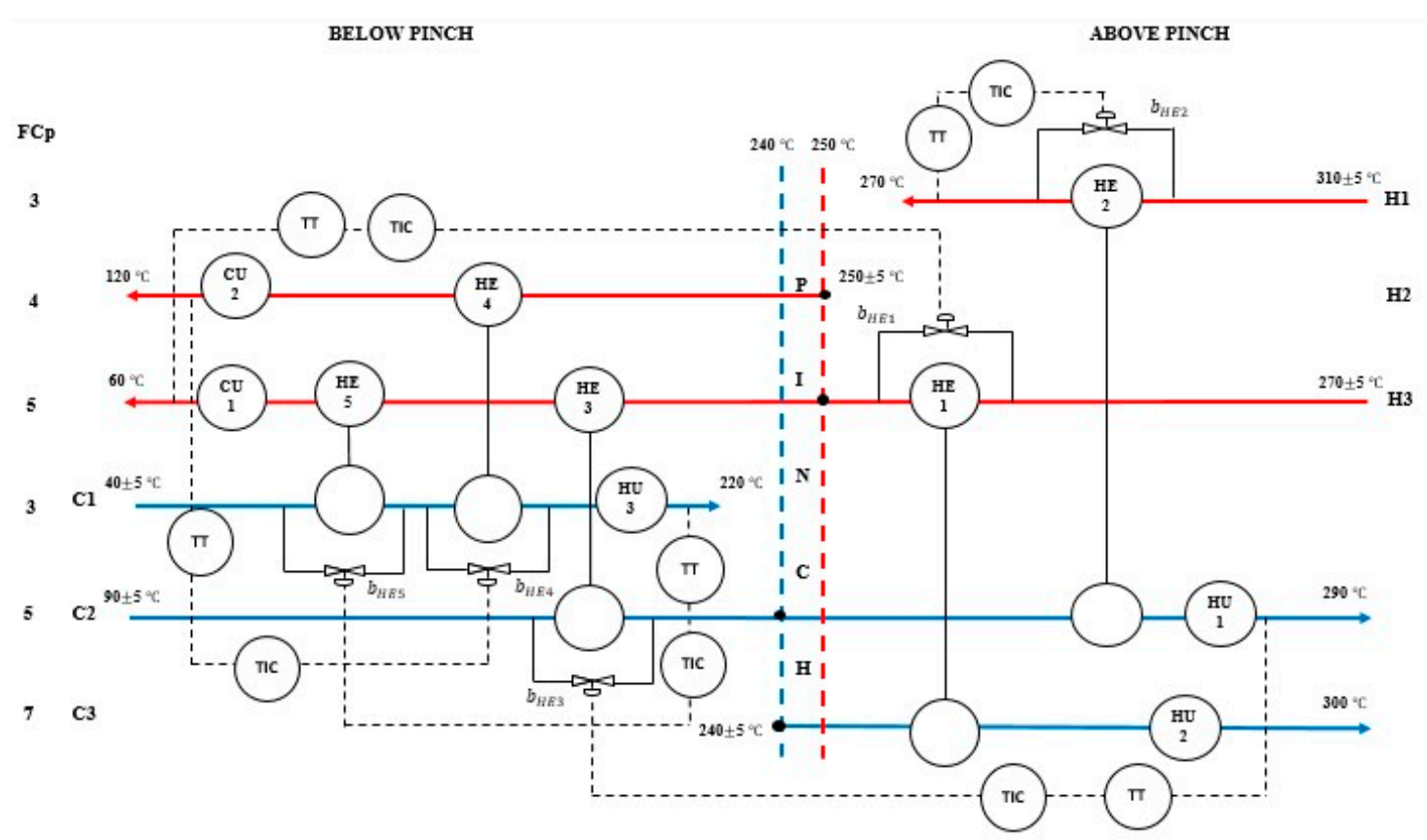

Figure 17. Overall HEN with bypass placement. 
Table 3. Analysis of bypass and utility requirements of HEN design.

\begin{tabular}{|c|c|c|c|c|c|c|c|c|c|c|c|c|c|}
\hline \multirow[t]{2}{*}{ Stream } & \multirow{2}{*}{$\begin{array}{l}\text { Stream } \\
\text { Position }\end{array}$} & \multirow{2}{*}{$\begin{array}{c}\text { Disturbance } \\
\text { at } T_{S}\left({ }^{\circ} \mathrm{C}\right)\end{array}$} & \multirow{2}{*}{$\begin{array}{c}\text { HE } \\
\text { Affected }\end{array}$} & \multirow{2}{*}{$\begin{array}{l}\text { HE Max. } \\
\text { Size } \\
\text { (MW) }\end{array}$} & \multirow{2}{*}{$\begin{array}{c}\text { HE Duty } \\
\text { during } \\
\text { Disturbance } \\
\text { (MW) }\end{array}$} & \multirow{2}{*}{$\begin{array}{l}\text { Bypass } \\
\text { Name }\end{array}$} & \multirow{2}{*}{$\begin{array}{l}\text { Bypass } \\
\text { Fraction } \\
\text { (1) }\end{array}$} & \multirow{2}{*}{$\begin{array}{l}\text { Bypass } \\
\text { Location }\end{array}$} & \multirow{2}{*}{$\begin{array}{l}\text { HU or CU } \\
\text { Affected }\end{array}$} & \multicolumn{2}{|c|}{$\begin{array}{c}\text { The Maximum } \\
\text { Size of } \\
\text { HU or CU }\end{array}$} & \multicolumn{2}{|c|}{$\begin{array}{l}\text { The Duty of HU or } \\
\text { CU during a } \\
\text { Disturbance }\end{array}$} \\
\hline & & & & & & & & & & $\begin{array}{l}\mathrm{HU} \\
\text { (MW) }\end{array}$ & $\begin{array}{l}\mathrm{CU} \\
\text { (MW) }\end{array}$ & $\begin{array}{l}\text { HU } \\
\text { (MW) }\end{array}$ & $\begin{array}{l}\mathrm{CU} \\
\text { (MW) }\end{array}$ \\
\hline \multirow{3}{*}{$\mathrm{H} 1$} & \multirow{3}{*}{ Above Pinch } & $+5{ }^{\circ} \mathrm{C}$ & HE2 & \multirow{3}{*}{135} & 135 & \multirow{3}{*}{$b_{\mathrm{HE} 2}$} & 0.000 & \multirow{3}{*}{$\begin{array}{c}\text { Stream } \\
\text { H1 }\end{array}$} & HU1 & \multirow{3}{*}{145} & \multirow{3}{*}{ - } & 115 & - \\
\hline & & Nominal & - & & 120 & & 0.111 & & - & & & 130 & - \\
\hline & & $-5^{\circ} \mathrm{C}$ & HE2 & & 105 & & 0.222 & & HU1 & & & 145 & - \\
\hline \multirow{3}{*}{$\mathrm{H} 2$} & \multirow{3}{*}{ Below Pinch } & $+5^{\circ} \mathrm{C}$ & HE4 & \multirow{3}{*}{520} & 520 & \multirow{3}{*}{$\mathrm{b}_{\mathrm{HE} 4}$} & 0.000 & \multirow{3}{*}{$\begin{array}{l}\text { Stream } \\
\quad \text { C1 }\end{array}$} & CU1 & \multirow{3}{*}{20} & \multirow{3}{*}{20} & 0 & 20 \\
\hline & & Nominal & - & & 520 & & 0.000 & & - & & & 0 & 0 \\
\hline & & $-5^{\circ} \mathrm{C}$ & HE4 & & 500 & & 0.038 & & HU3 & & & 20 & 0 \\
\hline \multirow{3}{*}{$\mathrm{H} 3$} & \multirow{3}{*}{ Across Pinch } & $+5^{\circ} \mathrm{C}$ & HE1 & \multirow{3}{*}{125} & 125 & \multirow{3}{*}{$b_{\mathrm{HE} 1}$} & 0.000 & \multirow{3}{*}{$\begin{array}{l}\text { Stream } \\
\text { H3 }\end{array}$} & HU2 & \multirow{3}{*}{320} & & 295 & 180 \\
\hline & & Nominal & - & & 125 & & 0.000 & & HU2 \& CU2 & & 180 & 295 & 155 \\
\hline & & $-5^{\circ} \mathrm{C}$ & HE1 & & 100 & & 0.200 & & CU2 & & & 320 & 155 \\
\hline & & $+5{ }^{\circ} \mathrm{C}$ & HE5 & & 5 & & 0.857 & & CU2 & & & - & 195 \\
\hline $\mathrm{C} 1$ & Below Pinch & Nominal & - & 35 & 20 & $\mathrm{~b}_{\mathrm{HE} 5}$ & 0.429 & Stream & - & - & 195 & - & 180 \\
\hline & & $-5^{\circ} \mathrm{C}$ & HE5 & & 35 & & 0.000 & C1 & CU2 & & & - & 165 \\
\hline & & $+5^{\circ} \mathrm{C}$ & HE3 & & 750 & & 0.032 & & HU1 & & & 105 & 180 \\
\hline $\mathrm{C} 2$ & Across Pinch & Nominal & - & 775 & 775 & $\mathrm{~b}_{\mathrm{HE} 3}$ & 0.000 & Stream & HU1 \& CU2 & 130 & 180 & 105 & 155 \\
\hline & & $-5^{\circ} \mathrm{C}$ & HE3 & & 775 & & 0.000 & C2 & CU2 & & & 130 & 155 \\
\hline & & $+5^{\circ} \mathrm{C}$ & HE1 & & 100 & & - & & HU2 & & & 285 & - \\
\hline C3 & Above Pinch & Nominal & - & 100 & 100 & - & - & - & - & 355 & - & 320 & - \\
\hline & & $-5^{\circ} \mathrm{C}$ & HE1 & & 100 & & - & & HU2 & & & 355 & - \\
\hline
\end{tabular}




\section{Case Studies}

Illustrative case studies extracted from the literature are used to verify the applicability and accuracy of the proposed methodology for optimal HEN synthesis, considering the uncertainties at the supply temperature.

\section{Case Study 1}

The first example is based on a methanol synthesis process adapted from Kijevčanin et al. [29]. The Case Study 1 has $\Delta \mathrm{T}_{\min }$ of $20^{\circ} \mathrm{C}$. The pinch temperature is at $357.2^{\circ} \mathrm{C}$. The minimum heating requirement $\left(\mathrm{Q}_{\mathrm{H} / \mathrm{min}}\right)$ is $1953.88 \mathrm{~kW}$ while the minimum cooling requirement $\left(\mathrm{Q}_{\mathrm{C} / \mathrm{min}}\right)$ is $3463.53 \mathrm{~kW}$. Expected variations of $\pm 10^{\circ} \mathrm{C}$ in the inlet temperature of streams $\mathrm{H} 1$ and $\mathrm{C} 3$ are assumed to vary from their nominal values. The case study consists of eight hot streams and three cold streams as shown in Table 4. Four scenarios involving the variations of the inlet temperatures between streams $\mathrm{H} 1$ and $\mathrm{C} 3$ are observed (Table 5).

Table 4. Stream data of Case Study 1 [29].

\begin{tabular}{ccccc}
\hline Stream & $\begin{array}{c}\text { Supply } \\
\text { Temperature, } \\
\mathbf{T}_{\mathbf{S}}\left({ }^{\circ} \mathbf{C}\right)\end{array}$ & $\begin{array}{c}\text { Target } \\
\text { Temperature, } \\
\left.\mathbf{T}_{\mathbf{t}} \mathbf{(}^{\circ} \mathbf{C}\right)\end{array}$ & $\begin{array}{c}\text { Heat Capacity } \\
\text { Flowrate, } \\
\text { FC }_{\mathbf{P}}\left(\mathbf{( k W} \mathbf{I}^{\circ} \mathbf{C}\right)\end{array}$ & $\begin{array}{c}\text { Enthalpy, } \\
\mathbf{\Delta H}(\mathbf{k W})\end{array}$ \\
\hline Hot 1 (H1) & $424.2 \pm 10$ & 120 & 4.6 & -1399.32 \\
Hot 2 (H2) & 342.1 & 120 & 5 & -1110.50 \\
Hot 3 (H3) & 342.2 & 120 & 5 & -1111.00 \\
Hot 4 (H4) & 343.1 & 160 & 5.1 & -933.81 \\
Hot 5 (H5) & 403.1 & 210 & 5.2 & -1004.12 \\
Hot 6 (H6) & 60.6 & 30 & 2.5 & -76.50 \\
Hot 7 (H7) & 98.9 & 30 & 1.1 & -75.79 \\
Hot 8 (H8) & 76.4 & 30 & 0.3 & -13.92 \\
Cold 1 (C1) & 349.7 & 450 & 19.2 & 1925.76 \\
Cold 2 (C2) & 37.7 & 450 & 5 & 2061.50 \\
Cold 3 (C3) & $14.5 \pm 10$ & 70 & 4.1 & 227.55 \\
\hline
\end{tabular}

Table 5. Uncertain parameters for the considered inlet temperatures.

\begin{tabular}{ccc}
\hline Scenario & $\mathrm{T}_{\mathrm{S}, \mathrm{H} 1}\left({ }^{\circ} \mathrm{C}\right)$ & $\mathrm{T}_{\mathrm{S}, \mathrm{C} 3}\left({ }^{\circ} \mathrm{C}\right)$ \\
\hline $\mathrm{A}$ & 434.2 & 24.5 \\
$\mathrm{~B}$ & 414.2 & 4.5 \\
$\mathrm{C}$ & 434.2 & 4.5 \\
$\mathrm{D}$ & 414.2 & 24.5 \\
\hline
\end{tabular}

All the scenarios are applied in designing a HEN with the nominal HE area (previous work) and the maximum HE area (this work). Figure 18 shows the HEN at the nominal condition with the bypass placement but with different HE area and bypass fraction.

Analysis of the effect of disturbances on streams H1 and C3 for the nominal HE area (previous work) is shown in Table 6 while the maximum HE area (this work) is shown in Table 7. It is observed that the duty of HE2 increased to $319.70 \mathrm{~kW}$ when the supply temperature of hot stream H1 located across or above the pinch increased. This decreased the duty of hot utility HU2 to $181.80 \mathrm{~kW}$. However, if the HE2 area is maintained at the nominal size, the duty of hot utility is also maintained at the nominal value. On the other hand, the duty of HE2 for both works decreased to $227.70 \mathrm{~kW}$ when the supply temperature of hot stream $\mathrm{H} 1$ is decreased. This led to an increase of hot utility HU2 to $273.80 \mathrm{~kW}$ in both works. For the cold stream C3 located below the pinch, it is observed that the duty of HE5 decreased to $186.60 \mathrm{~kW}$ when the supply temperature is increased for both works. Both designs 
required large HU2 utility loads to cope with the deficit enthalpy of HE5. On the contrary, the duty of HE5 can be increased to $256.60 \mathrm{~kW}$, at the maximum HE area when the supply temperature of C3 decreased. Consequently, the minimum cold utility for CU2 can be obtained.

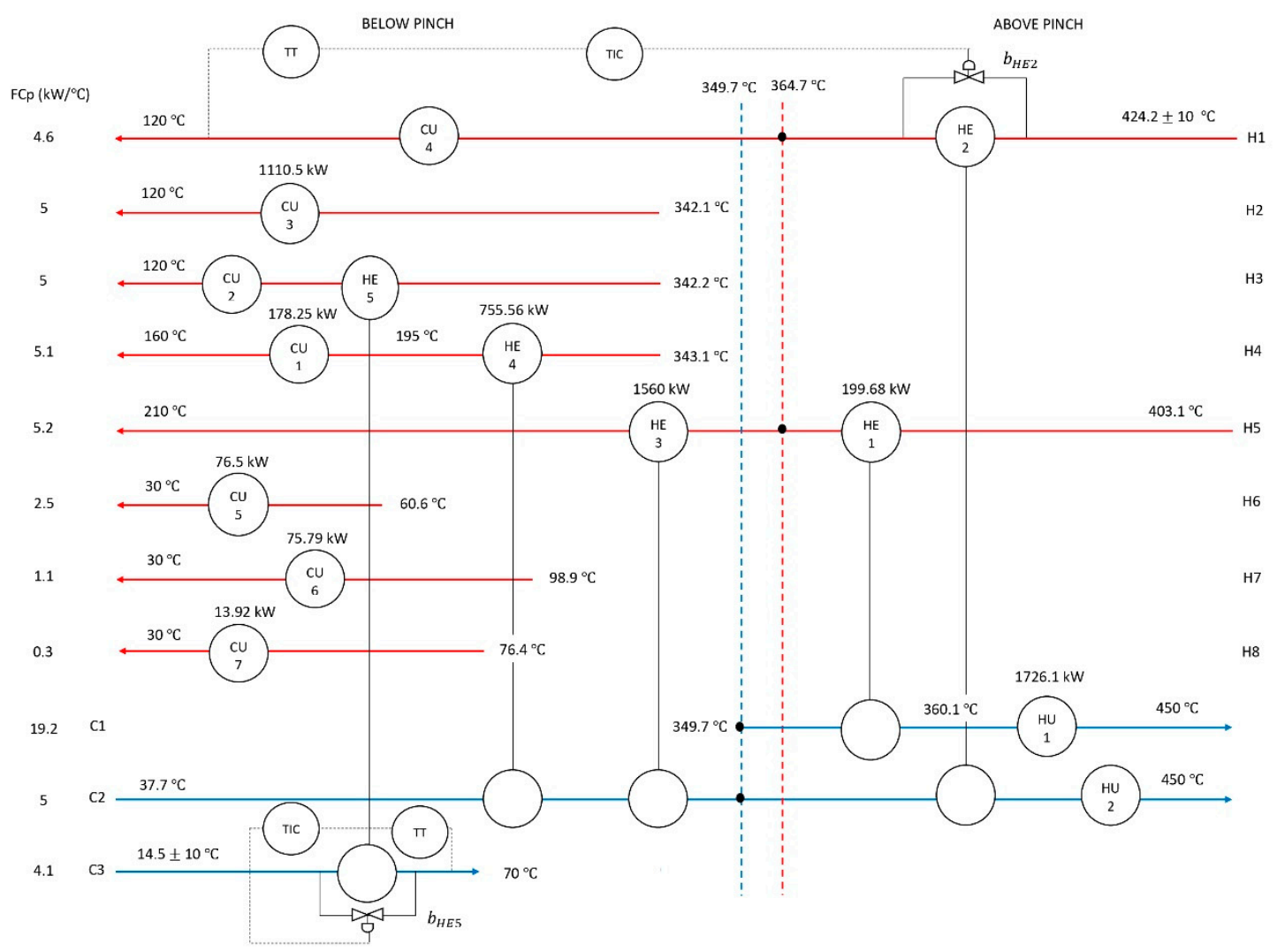

Figure 18. Overall HEN with bypass placement for Case Study 1.

The impact of the changes on the economics for the cases of nominal HE area and maximum HE area were analysed by comparing the annualised capital and utility costs for both HEN using Equation (5) [30]. The basic rule to target for cost-effective minimum utilities is to maximise the use of higher temperature cold utilities and lower temperature hot utilities. The type of utilities suggested based on temperature interval is shown in Table 8. The rates for the utilities refer to Sun et al. [31].

$$
\text { Annualised capital cost }=\text { Annualised factor } \times\left(1300+1000 \mathrm{~A}^{0.83}\right)
$$

where the annualised factor is 0.298 .

Table 9 compares the heat recovery and economic performance of HEN with nominal HE area and maximum HE area for all the scenarios. Results of this study show that the new heuristics can guide the user to manage temperature disturbances in HEN design for maximum heat recovery with minimum total costs. Although this work has a high annualised capital cost due to larger HE area compared to the previous work, the annualised total costs for scenarios A, B and C is still much cheaper than the previous work. For scenario D, the total annualised cost is $0.16 \%$ higher due to the large HE area, but the utility load remains the same. 
Table 6. Analysis of bypass and utility requirements of HEN design with nominal HE area.

\begin{tabular}{|c|c|c|c|c|c|c|c|c|c|c|c|c|c|}
\hline \multirow[t]{2}{*}{ Stream } & \multirow[t]{2}{*}{$\begin{array}{l}\text { Stream } \\
\text { Position }\end{array}$} & \multirow{2}{*}{$\begin{array}{c}\text { Disturbance } \\
\text { at } \mathrm{T}_{\mathrm{S}} \\
\left({ }^{\circ} \mathrm{C}\right)\end{array}$} & \multirow[t]{2}{*}{$\begin{array}{c}\text { HE } \\
\text { Affected }\end{array}$} & \multirow{2}{*}{$\begin{array}{l}\text { HE Max. } \\
\text { Size } \\
(\mathrm{kW})\end{array}$} & \multirow{2}{*}{$\begin{array}{c}\text { HE Duty } \\
\text { during } \\
\text { Disturbance } \\
(\mathrm{kW})\end{array}$} & \multirow[t]{2}{*}{$\begin{array}{l}\text { Bypass } \\
\text { Name }\end{array}$} & \multirow[t]{2}{*}{$\begin{array}{l}\text { Bypass } \\
\text { Fraction }\end{array}$} & \multirow[t]{2}{*}{$\begin{array}{l}\text { Bypass } \\
\text { Location }\end{array}$} & \multirow{2}{*}{$\begin{array}{c}\text { HU or } \\
\text { CU } \\
\text { Affected }\end{array}$} & \multicolumn{2}{|c|}{$\begin{array}{c}\text { The Maximum Size } \\
\text { of HU or CU }\end{array}$} & \multicolumn{2}{|c|}{$\begin{array}{l}\text { The Duty of HU or } \\
\text { CU during a } \\
\text { Disturbance }\end{array}$} \\
\hline & & & & & & & & & & HU (kW) & CU (kW) & HU (kW) & CU (kW) \\
\hline \multirow{3}{*}{$\mathrm{H} 1$} & \multirow{3}{*}{$\begin{array}{l}\text { Across } \\
\text { Pinch }\end{array}$} & $+10^{\circ} \mathrm{C}$ & HE2 & & 273.70 & \multirow{3}{*}{$b_{\mathrm{HE} 2}$} & 0.000 & \multirow{3}{*}{$\begin{array}{l}\text { Stream } \\
\text { H1 }\end{array}$} & HU2 & \multirow{3}{*}{273.80} & \multirow{3}{*}{. } & 227.80 & - \\
\hline & & Nominal & - & 273.70 & 273.70 & & 0.000 & & - & & & 227.80 & - \\
\hline & & $-10{ }^{\circ} \mathrm{C}$ & HE2 & & 227.70 & & 0.168 & & HU2 & & & 273.80 & - \\
\hline \multirow{3}{*}{$\mathrm{C} 3$} & \multirow{3}{*}{$\begin{array}{l}\text { Below } \\
\text { Pinch }\end{array}$} & $+10^{\circ} \mathrm{C}$ & HE5 & \multirow{3}{*}{227.55} & 186.60 & & 0.000 & \multirow{3}{*}{$\begin{array}{l}\text { Stream } \\
\text { C3 }\end{array}$} & CU2 & \multirow{3}{*}{-} & \multirow{3}{*}{924.45} & - & 924.45 \\
\hline & & Nominal & - & & 227.55 & $b_{\text {HE5 }}$ & 0.000 & & - & & & - & 883.45 \\
\hline & & $-10{ }^{\circ} \mathrm{C}$ & HE5 & & 227.55 & & 0.153 & & CU2 & & & - & 883.45 \\
\hline
\end{tabular}

Table 7. Analysis of bypass and utility requirements of HEN design with maximum HE area.

\begin{tabular}{|c|c|c|c|c|c|c|c|c|c|c|c|c|c|}
\hline \multirow[t]{2}{*}{ Stream } & \multirow[t]{2}{*}{$\begin{array}{l}\text { Stream } \\
\text { Position }\end{array}$} & \multirow{2}{*}{$\begin{array}{c}\text { Disturbance } \\
\text { at } T_{S} \\
\text { ( C) }\end{array}$} & \multirow[t]{2}{*}{$\begin{array}{c}\text { HE } \\
\text { Affected }\end{array}$} & \multirow{2}{*}{$\begin{array}{c}\text { HE Max. } \\
\text { Size } \\
(\mathbf{k W})\end{array}$} & \multirow{2}{*}{$\begin{array}{c}\text { HE Duty } \\
\text { during } \\
\text { Disturbance } \\
(\mathbf{k W})\end{array}$} & \multirow[t]{2}{*}{$\begin{array}{c}\text { Bypass } \\
\text { Name }\end{array}$} & \multirow{2}{*}{$\begin{array}{c}\text { Bypass } \\
\text { Fraction } \\
\text { (1) }\end{array}$} & \multirow[t]{2}{*}{$\begin{array}{l}\text { Bypass } \\
\text { Location }\end{array}$} & \multirow{2}{*}{$\begin{array}{c}\text { HU or } \\
\text { CU } \\
\text { Affected }\end{array}$} & \multicolumn{2}{|c|}{$\begin{array}{c}\text { The Maximum Size } \\
\text { of HU or CU }\end{array}$} & \multicolumn{2}{|c|}{$\begin{array}{c}\text { The Duty of HU or } \\
\text { CU during a } \\
\text { Disturbance }\end{array}$} \\
\hline & & & & & & & & & & HU (kW) & CU (kW) & HU (kW) & CU (kW) \\
\hline \multirow{3}{*}{ H1 } & \multirow{3}{*}{$\begin{array}{l}\text { Across } \\
\text { Pinch }\end{array}$} & $+10^{\circ} \mathrm{C}$ & HE2 & \multirow{3}{*}{319.70} & 319.70 & & 0.000 & \multirow{3}{*}{$\begin{array}{l}\text { Stream } \\
\text { H1 }\end{array}$} & HU2 & \multirow{3}{*}{273.80} & \multirow{3}{*}{ - } & 181.80 & - \\
\hline & & Nominal & - & & 273.70 & $b_{\mathrm{HE} 2}$ & 0.252 & & - & & & 227.80 & - \\
\hline & & $-10^{\circ} \mathrm{C}$ & HE2 & & 227.70 & & 0.288 & & HU2 & & & 273.80 & - \\
\hline \multirow{3}{*}{$\mathrm{C} 3$} & \multirow{3}{*}{$\begin{array}{l}\text { Below } \\
\text { Pinch }\end{array}$} & $+10^{\circ} \mathrm{C}$ & HE5 & \multirow{3}{*}{268.60} & 186.60 & & 0.305 & \multirow{3}{*}{$\begin{array}{l}\text { Stream } \\
\quad \text { C3 }\end{array}$} & CU2 & \multirow{3}{*}{-} & \multirow{3}{*}{924.45} & - & 924.45 \\
\hline & & Nominal & - & & 227.55 & $b_{\text {HE5 }}$ & 0.265 & & - & & & - & 883.45 \\
\hline & & $-10{ }^{\circ} \mathrm{C}$ & HE5 & & 268.60 & & 0.000 & & CU2 & & & - & 842.45 \\
\hline
\end{tabular}

Table 8. Multiple utilities data [19].

\begin{tabular}{cccc}
\hline Utilities & $\mathbf{T}_{\mathbf{S}}\left({ }^{\circ} \mathbf{C}\right)$ & $\mathbf{T}_{\mathbf{t}}\left({ }^{\circ} \mathbf{C}\right)$ & Rate $(\mathbf{U S D} / \mathbf{k W} \cdot \mathbf{y})$ \\
\hline Hot oil & 350 & 320 & 311.280 \\
High pressure steam (HPS) & 255 & 254 & 249.024 \\
Tempered water (TW) & 70 & 80 & 31.128 \\
Cooling water $(\mathrm{CW})$ & 25 & 30 & 41.504 \\
\hline
\end{tabular}


Table 9. Comparison results of HEN total annual cost for Case Study 1.

\begin{tabular}{|c|c|c|c|c|c|c|c|c|}
\hline & \multicolumn{4}{|c|}{ Previous Work (with Nominal HE Area) } & \multicolumn{4}{|c|}{ This Work (with Maximum HE Area) } \\
\hline & Scenario A & Scenario B & Scenario C & Scenario D & Scenario A & Scenario B & Scenario C & Scenario D \\
\hline Cold utility (kW) & 924.45 & 883.45 & 883.45 & 924.45 & 924.45 & 842.45 & 842.45 & 924.45 \\
\hline Hot utility $(\mathrm{kW})$ & 227.80 & 273.80 & 227.80 & 273.80 & 181.80 & 273.80 & 181.80 & 273.80 \\
\hline Total disturbed HE area $\left(\mathrm{m}^{2}\right)$ & \multirow{2}{*}{\multicolumn{4}{|c|}{$\begin{array}{l}77.774 \\
5705.92\end{array}$}} & \multirow{2}{*}{\multicolumn{4}{|c|}{$\begin{array}{c}82.186 \\
5901.70\end{array}$}} \\
\hline Annualised capital cost $(\$ / y)$ & & & & & & & & \\
\hline Annualised utility cost $(\$ / y)$ & $99,685.86$ & $112,728.50$ & 98.409 .62 & $114,004.74$ & $85,366.98$ & $111,452.25$ & $82,814.49$ & $114,004.74$ \\
\hline Annualised total cost $(\$ / y)$ & $105,391.78$ & $118,434.42$ & $104,115.54$ & $119,710.66$ & $91,268.68$ & $117,353.95$ & $88,716.19$ & $119,906.44$ \\
\hline
\end{tabular}




\section{Case Study 2}

In this case study, the proposed methodology is applied to solve an illustrative example with three hot streams and three cold streams. The data used for this case study are adapted from the work of Escobar et al. [9]. The nominal data for the problem is listed in Table 10. The expected variations in the inlet temperatures are assumed $\pm 10 \mathrm{~K}$ with $\Delta \mathrm{T}_{\min }$ of $10 \mathrm{~K}$. In contrast to Escobar et al. [9], the nominal configuration of HEN is maintained. The maximum heat exchanger area approach is applied to increase the flexibility of HEN due to the uncertainty of operating conditions. The uncertain parameters considered in the design are given in Table 11.

Table 10. Stream data of Case Study 2 [9].

\begin{tabular}{|c|c|c|c|c|}
\hline Stream & $\begin{array}{c}\text { Supply } \\
\text { Temperature, } \\
\mathrm{T}_{\mathrm{S}}(\mathrm{K})\end{array}$ & $\begin{array}{c}\text { Target } \\
\text { Temperature, } \\
\mathbf{T}_{\mathbf{t}}(\mathrm{K})\end{array}$ & $\begin{array}{c}\text { Heat Capacity } \\
\text { Flowrate, FC } \\
(\mathbf{k W} / \mathrm{K})\end{array}$ & $\mathrm{h}\left(\mathrm{kW} \cdot \mathrm{m}^{2} / \mathrm{K}\right)$ \\
\hline Hot 1 (H1) & $583 \pm 10$ & 323 & 1.4 & 0.16 \\
\hline Hot 2 (H2) & $723 \pm 10$ & 553 & 2.0 & 0.16 \\
\hline Cold 1 (C1) & $313 \pm 10$ & 393 & 3.0 & 0.16 \\
\hline Cold 2 (C2) & $388 \pm 10$ & 553 & 2.0 & 0.16 \\
\hline $\mathrm{CU}$ & 303 & 323 & & 0.16 \\
\hline $\mathrm{HU}$ & 573 & 573 & & 0.16 \\
\hline
\end{tabular}

Exchanger capital cost $(\$ / y)=8333.3+641.7$ Area $\left(\mathrm{m}^{2}\right)$

Annualisation factor $=0.2 / \mathrm{y}$

Cost of cooling utility $=60.576(\$ / \mathrm{kW} \cdot \mathrm{y})$

Cost of heating utility $=171.428(\$ / \mathrm{kW} \cdot \mathrm{y})$

Table 11. Uncertain parameters for the points considered.

\begin{tabular}{ccccc}
\hline Iteration & $\mathbf{T}_{\mathbf{S}, \mathbf{H} 1}(\mathbf{K})$ & $\mathbf{T}_{\mathbf{S}, \mathbf{H} \mathbf{2}}(\mathbf{K})$ & $\mathbf{T}_{\mathbf{S}, \mathbf{C} \mathbf{1}}(\mathbf{K})$ & $\mathbf{T}_{\mathbf{S}, \mathrm{C} 2}(\mathbf{K})$ \\
\hline 1 & 583 & 723 & 313 & 388 \\
2 & 573 & 713 & 303 & 378 \\
\hline
\end{tabular}

Initially, the MER for the nominal case (without disturbances) is determined by using pinch analysis targeting methods. For this case study, the nominal condition corresponds to the first iteration. By using the same (nominal) HEN configuration, in order for the target temperature to be achieved, the enthalpy for the cold streams is required to be increased while the enthalpy for the hot streams is decreased. Thus, the utility consumption (cold utility) can be reduced. At the same time, the area of the heat exchangers is required to be at the maximum size for the HEN design to be feasible. Figure 19 shows the HEN at the nominal condition with the bypass placement. On the other hand, Escobar et al. [9] suggested two different HEN designs for each iteration as the nominal design is not feasible for the variations up to $10 \mathrm{~K}$ in the inlet temperatures. The steps where the critical point is added to the nominal conditions and the multi-period optimisation problem needs to be repeated until the flexibility is accomplished. The new HEN configuration is designed with high flexibility. The TAC is comprised of the annualised utility cost and annualised capital cost. The TAC of this work for the first iteration is much higher than the previous work as the same HEN design with maximum heat exchanger area is applied. However, the TAC for this work with the consideration of uncertainty is $\$ 25,986.93 / y$, comprising $\$ 3028.80 / y$ associated with operating expenses (utility consumption) and $\$ 22,958.13 / \mathrm{y}$ to capital investment. This work gives $4 \% / \mathrm{y}$ lower TAC compared to the work of Escobar et al. [9]. Although it has a higher capital cost, the utility consumption is reduced. This method is able to give positive effects even though the HEN has uncertain operating parameters, as it provides better utility usage and would be a good approach for considering a reduction in the 
environmental impact associated with the use of fossil-based energy sources. The results of this work and those of Escobar et al. [9] are compared in Table 12.

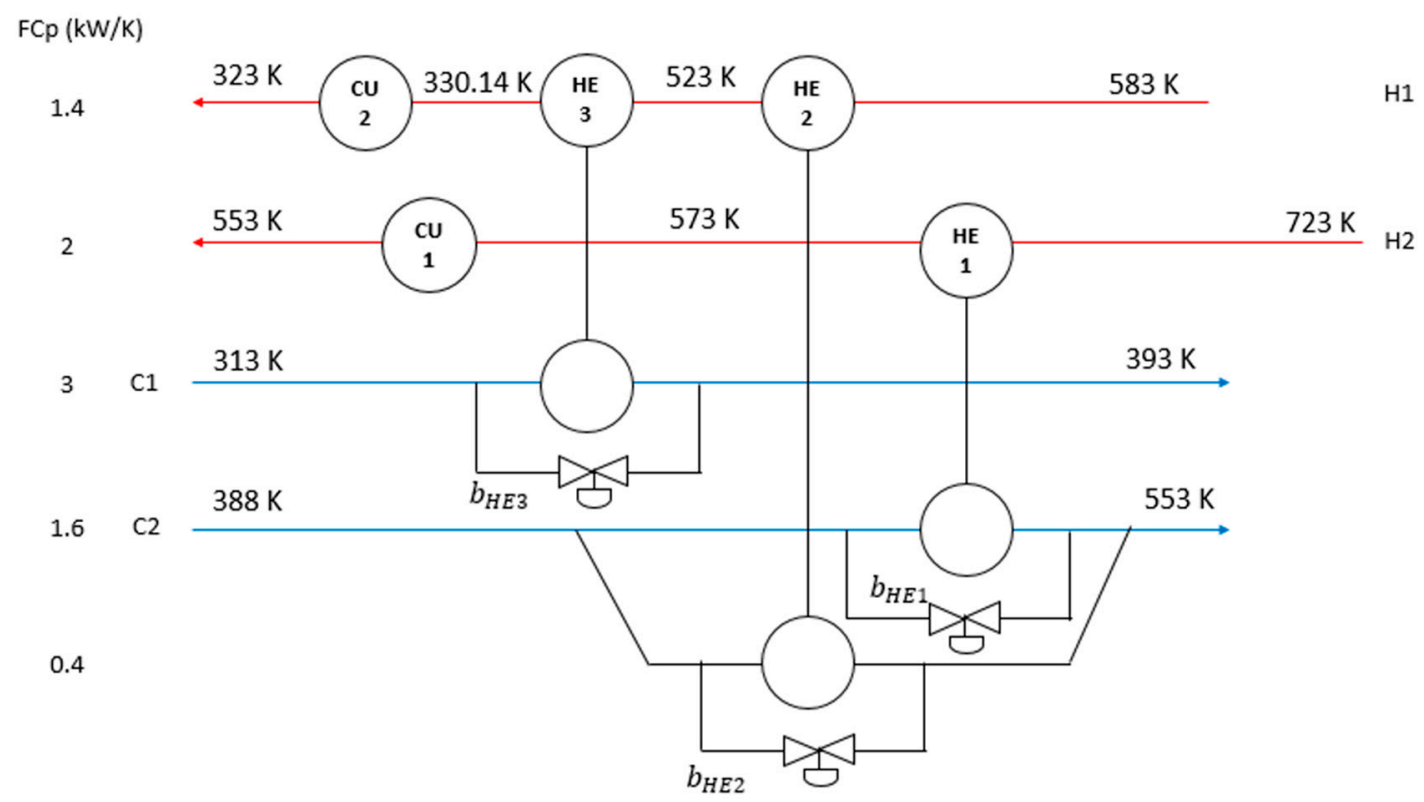

Figure 19. Overall HEN with bypass placement for Case Study 2.

Table 12. Comparison results of HEN total annual cost for Case Study 2.

\begin{tabular}{ccc|cc}
\hline Method & \multicolumn{2}{c|}{ Escobar et al. [9] } & \multicolumn{2}{c}{ This Work } \\
\hline Iteration & 1 & 2 & 1 & 2 \\
Annualised utility cost $(\$ / y)$ & 8117.00 & 5573.00 & 8117.00 & 3028.80 \\
Total affected area $\left(\mathrm{m}^{2}\right)$ & 81.417 & 103.631 & 113.9538 & 113.9538 \\
Annualised capital cost $(\$ / \mathrm{y})$ & $17,115.70$ & $21,633.30$ & $22,958.13$ & $22,958.13$ \\
Total annualised cost $(\$ / \mathrm{y})$ & $25,232.70$ & $27,206.30$ & $31,075.13$ & $25,986.93$ \\
\hline
\end{tabular}

\section{Conclusions}

Heat exchanger network configuration can influence disturbance propagation and process behaviour, as well as limit process controllability and operability. A systematic methodology has been developed in this work to manage temperature disturbances and make a heat exchanger network more flexible and operable toward achieving the maximum heat recovery. The method considers the impact of supply temperature fluctuations on utility consumption, heat exchanger sizing and bypass placement. The maximum energy recovery targets are determined for the nominal case (without disturbances) by using pinch analysis targeting methods. The steps to manage the fluctuating supply temperature in the heat exchanger network to achieve target temperature and maximum energy recovery are defined in three stages: (1) the effect of increasing or decreasing supply temperature on the hot and cold streams energy requirement; (2) the fundamental theory of the plus-minus principle; (3) the effect of $T_{S}$ fluctuation on utilities based on the plus-minus principle. From all these steps, key observations were made and new heuristics based on the plus-minus principle of pinch analysis have been introduced for heat exchanger network design in maximising utility savings. The heuristics were applied by simulating various scenarios of disturbances occurring in the process streams of the heat exchanger network. Guidelines on the sizing of heat exchangers and bypass locations and fractions have also been proposed. The grid diagram and temperature vs enthalpy plot were used to illustrate the effect of changes in design and operating parameters. This approach involves a trade-off between the utility cost and capital cost of the affected heat exchangers. Application of the method on two case studies showed that the configuration of the heat exchanger network is maintained for all the scenarios. In addition, the exchanger areas are designed at the maximum size with a bypass to handle 
the most critical uncertainty of operating conditions while minimising the utility usage. It showed that this method improved the annualised utility cost by up to $89 \%$. Previous works in the literature required the exchanger area adjustment during the operation and have several heat exchanger network configurations for each scenario. Nevertheless, in industry, the configuration and area should be fixed during the operation even with unforeseen uncertainty. The modification of heat exchanger network design during the operation will be costly. This work is beneficial as it has a reduced utility usage and a higher capital cost.

Major novelties introduced by this work include:

- The approach is able to handle the most critical uncertainty of operating conditions with the maximum heat exchanger areas while minimising the utility usage.

- The nominal configuration of HEN based on pinch analysis is maintained and controlled by the bypass.

- The effect of uncertain operating conditions on the heat exchange and utility consumption can be easily visualised through the plus-minus principle.

- The proposed new heuristics based on the plus-minus principle of pinch analysis can be applied for all problems.

However, overdesign factors could affect the annualised capital cost of heat exchanger networks. Future research should also include the probability of disturbances occurring in the heat exchanger network. This probability may influence the requirement of the maximum heat exchanger size in the design as well as the total annualised cost.

Author Contributions: Conceptualisation, S.R.W.A.; Methodology, A.M.H., S.R.W.A.; Validation, A.M.H.; Formal analysis, A.M.H., S.R.W.A.; Writing—original draft preparation, A.M.H.; writing-review and editing, S.R.W.A., Z.A.M., J.J.K.; supervision, S.R.W.A., Z.A.M., J.J.K., M.K.A.H.

Acknowledgments: The authors thank Universiti Teknologi Malaysia (UTM) for providing research funds for this project under Vote Number Q.J130000.3509.05G96, Q.J130000.2509.19H34, the Fundamental Research Grant Scheme under Ministry of Education with Vote Number R.J130000.7809.4F918 and from the EC project for Sustainable Process Integration Laboratory-SPIL (Project No. CZ.02.1.01/0.0/0.0/15_003/0000456) funded by Czech Republic Operational Program Research and Development, Education, Priority 1: Strengthening capacity for quality research in collaboration agreement with Universiti Teknologi Malaysia (UTM).

Conflicts of Interest: The authors declare no conflict of interest.

\section{Nomenclature}

$\mathrm{FC}_{\mathrm{p}} \quad$ Heat capacity flowrate, $\mathrm{kW} /{ }^{\circ} \mathrm{C}$ or $\mathrm{MW} /{ }^{\circ} \mathrm{C}$

$\mathrm{Q}_{\mathrm{C}, \min } \quad$ Minimum cold utility, $\mathrm{kW}$ or $\mathrm{MW}$

$\mathrm{Q}_{\mathrm{H} \text {,min }} \quad$ Minimum hot utility, $\mathrm{kW}$ or $\mathrm{MW}$

$\mathrm{T}_{0}^{\mathrm{h}} \quad$ Outlet hot temperature, ${ }^{\circ} \mathrm{C}$

$\mathrm{T}_{0}^{\mathrm{c}} \quad$ Outlet cold temperature, ${ }^{\circ} \mathrm{C}$

$\mathrm{T}_{\text {pinch }} \quad$ Pinch temperature, ${ }^{\circ} \mathrm{C}$

$\mathrm{T}_{\mathrm{S}} \quad$ Supply temperature, ${ }^{\circ} \mathrm{C}$

$\mathrm{T}_{\mathrm{S}}^{\mathrm{h}} \quad$ Supply hot temperature, ${ }^{\circ} \mathrm{C}$

$\mathrm{T}_{\mathrm{S}}^{\mathrm{c}} \quad$ Supply cold temperature, ${ }^{\circ} \mathrm{C}$

$\mathrm{T}_{\mathrm{t}} \quad$ Target temperature, ${ }^{\circ} \mathrm{C}$

$\mathrm{T}_{\mathrm{t}}^{\mathrm{h}} \quad$ Target hot temperature, ${ }^{\circ} \mathrm{C}$

$\mathrm{T}_{\mathrm{t}}^{\mathrm{c}} \quad$ Target cold temperature, ${ }^{\circ} \mathrm{C}$

$\mathrm{u}^{\text {h }} \quad$ Hot stream fraction

$\mathrm{u}^{\mathrm{b}} \quad$ Bypass fraction

$\mathrm{u}^{\mathrm{c}} \quad$ Cold stream fraction

$\Delta \mathrm{H} \quad$ Enthalpy, $\mathrm{kW}$ or $\mathrm{MW}$ 


\section{References}

1. Klemeš, J.J.; Kravanja, Z. Forty Years of Heat Integration: Pinch Analysis (PA) and Mathematical Programming (MP). Curr. Opin. Chem. Eng. 2013, 2, 461-474. [CrossRef]

2. Klemeš, J.J.; Varbanov, P.S.; Walmsley, T.G.; Jia, X. New Directions in the Implementation of Pinch Methodology (PM). Renew. Sustain. Energy Rev. 2018, 98, 439-468. [CrossRef]

3. Isafiade, A.J.; Short, M. Synthesis of Mass Exchange Networks for Single and Multiple Periods of Operations Considering Detailed Cost Functions and Column Performance. Process Saf. Environ. Prot. 2016, 103, 391-404. [CrossRef]

4. Sa, A.; Thollander, P.; Rafiee, M. Industrial Energy Management Systems and Energy-Related Decision-Making. Energies 2018, 11, 2784. [CrossRef]

5. Thollander, P.; Palm, J. Industrial Energy Management Decision Making for Improved Energy Efficiency-Strategic System Perspectives and Situated Action in Combination. Energies 2015, 8, 5694-5703. [CrossRef]

6. Marselle, D.F.; Morari, M.; Rudd, D.F. Design of Resilient Processing Plants-II Design and Control of Energy Management Systems. Chem. Eng. Sci. 1982, 37, 259-270. [CrossRef]

7. Hafizan, A.M.; Alwi, S.R.W.; Manan, Z.A.; Klemeš, J.J.; Hamid, M.K.A. Temperature Disturbance Management in Heat Exchanger Network for Maximum Energy Recovery. In Proceedings of the 13th SDWES Conference, Palermo, Italy, 30 September-4 October 2018; SDEWES2018-0484.

8. Linnhoff, B.; Kotjabasakis, E. Downstream Paths for Operable Process Design. Chem. Eng. Prog. 1986, 82, 23-28.

9. Escobar, M.; Trierweiler, J.O.; Grossmann, I.E. Simultaneous Synthesis of Heat Exchanger Networks with Operability Considerations: Flexibility and Controllability. Comput. Chem. Eng. 2013, 55, 158-180. [CrossRef]

10. Hafizan, A.M.; Alwi, S.R.W.; Manan, Z.A.; Klemeš, J.J. Optimal Heat Exchanger Network Synthesis with Operability and Safety Considerations. Clean Technol. Environ. Policy 2016, 18, 2381-2400. [CrossRef]

11. Čuček, L.; Kravanja, Z. A Procedure for the Retrofitting of Large-Scale Heat Exchanger Networks for Fixed and Flexible Designs. Chem. Eng. Trans. 2015, 45, 109-114.

12. Isafiade, A.J.; Short, M. Simultaneous Synthesis of Flexible Heat Exchanger Networks for Unequal Multi-Period Operations. Process Saf. Environ. Prot. 2016, 103, 377-390. [CrossRef]

13. Miranda, C.B.; Costa, C.B.; Caballero, J.A.; Ravagnani, M.A. Optimal Synthesis of Multiperiod Heat Exchanger Networks: A Sequential Approach. Appl. Therm. Eng. 2017, 115, 1187-1202. [CrossRef]

14. Kang, L.; Liu, Y. A Three-Step Method to Improve the Flexibility of Multiperiod Heat Exchanger Networks. Process Integr. Optim. Sustain. 2018, 2, 169-181. [CrossRef]

15. Narraway, L.T.; Perkins, J.D. Selection of Process Control Structure Based on Linear Dynamic Economics. Ind. Eng. Chem. Res. 1993, 32, 2681-2692. [CrossRef]

16. Walsh, S.; Perkins, J. Application of Integrated Process and Control System Design to Waste Water Neutralisation. Comput. Chem. Eng. 1994, 18, S183-S187. [CrossRef]

17. Bakar, S.H.A.; Hamid, M.K.A.; Alwi, S.R.W.; Manan, Z.A. Flexible and Operable Heat Exchanger Networks. Chem. Eng. 2013, 32, 1297-1302.

18. Kong, L.; Avadiappan, V.; Huang, K.; Maravelias, C.T. Simultaneous Chemical Process Synthesis and Heat Integration with Unclassified Hot/Cold Process Streams. Comput. Chem. Eng. 2017, 101, 210-225. [CrossRef]

19. Quirante, N.; Grossmann, I.E.; Caballero, J.A. Disjunctive Model for the Simultaneous Optimization and Heat Integration with Unclassified Streams and Area Estimation. Comput. Chem. Eng. 2018, 108, $217-231$. [CrossRef]

20. Onishi, V.C.; Quirante, N.; Ravagnani, M.A.; Caballero, J.A. Optimal Synthesis of Work and Heat Exchangers Networks Considering Unclassified Process Streams at Sub and Above-Ambient Conditions. Appl. Energy 2018, 224, 567-581. [CrossRef]

21. Quirante, N.; Caballero, J.A.; Grossmann, I.E. A Novel Disjunctive Model for the Simultaneous Optimization and Heat Integration. Comput. Chem. Eng. 2017, 96, 149-168. [CrossRef]

22. Linnhoff, B.; Vredeveld, R. Pinch Technology has Come of Age. Chem. Eng. Prog. 2017, 80, 33-40.

23. Chew, K.H.; Klemeš, J.J.; Alwi, S.R.W.; Manan, Z.A. Process Modifications to Maximise Energy Savings in Total Site Heat Integration. Appl. Therm. Eng. 2015, 78, 731-739. [CrossRef] 
24. Song, R.; Tang, Q.; Wang, Y.; Feng, X.; El-Halwagi, M.M. The Implementation of Inter-Plant Heat Integration Among Multiple Plants. Part I: A Novel Screening Algorithm. Energy 2017, 140, 1018-1029. [CrossRef]

25. Linnhoff, B.; Flower, J.R. Synthesis of Heat Exchanger Networks: I. Systematic Generation of Energy Optimal Networks. AIChE J. 1978, 24, 633-642. [CrossRef]

26. Alwi, S.R.W.; Manan, Z.A. STEP-A New Graphical Tool for Simultaneous Targeting and Design of A Heat Exchanger Network. Chem. Eng. J. 2010, 162, 106-121. [CrossRef]

27. Linnhoff, B.; Hindmarsh, E. The Pinch Design Method for Heat Exchanger Networks. Chem. Eng. Sci. 1983, 38, 745-763. [CrossRef]

28. Rathjens, M.; Bohnenstädt, T.; Fieg, G.; Engel, O. Synthesis of Heat Exchanger Networks Taking into Account Cost and Dynamic Considerations. Procedia Eng. 2016, 157, 341-348. [CrossRef]

29. Kijevčanin, M.L.; Đorđević, B.; Ocić, O.; Crnomarković, M.; Marić, M.; Šerbanović, S.P. Energy and Economy Savings in the Process of Methanol Synthesis Using Pinch Technology. J. Serbian Chem. Soc. 2004, 69, 827-837. [CrossRef]

30. Na, J.; Jung, J.; Park, C.; Han, C. Simultaneous Synthesis of a Heat Exchanger Network with Multiple Utilities Using Utility Substages. Comput. Chem. Eng. 2015, 79, 70-79. [CrossRef]

31. Sun, K.N.; Alwi, S.R.W.; Manan, Z.A. Heat Exchanger Network Cost Optimization Considering Multiple Utilities and Different Types of Heat Exchangers. Comput. Chem. Eng. 2013, 49, 194-204. [CrossRef]

(C) 2019 by the authors. Licensee MDPI, Basel, Switzerland. This article is an open access article distributed under the terms and conditions of the Creative Commons Attribution (CC BY) license (http://creativecommons.org/licenses/by/4.0/). 